\title{
Prominence Eruptions and Coronal Mass Ejection: A Statistical Study using Microwave Observations
}

\author{
N. Gopalswamy ${ }^{1}$, M. Shimojo ${ }^{2}$, W. Lu ${ }^{1,3}$, S. Yashiro ${ }^{1,3}$, K. Shibasaki ${ }^{2}$, and R. A. Howard ${ }^{4}$
}

\begin{abstract}
We present the results of a statistical study of a large number of solar prominence events (PEs) observed by the Nobeyama Radioheliograph. We studied the association rate, relative timing and spatial correspondence between PEs and coronal mass ejections (CMEs). We classified the PEs as radial and transverse, depending on whether the prominence moved predominantly in the radial or horizontal direction. The radial events were faster and attained a larger height above the solar surface than the transverse events. Out of the 186 events studied, $152(82 \%)$ were radial events, while only 34 (18\%) were transverse events. Comparison with white-light CME data revealed that 134 (72\%) PEs were clearly associated with CMEs. We compare our results with those of other studies involving PEs and white light CMEs in order to address the controversy in the rate of association between CMEs and prominence eruptions. We also studied the temporal and spatial relationship between prominence and CME events. The CMEs and PEs seem to start roughly at the same time. There was no solar cycle dependence of the temporal relationship. The spatial relationship was, however, solar cycle dependent. During the solar minimum, the central position angle of the CMEs had a tendency to be offset closer to the equator as compared to to that of the PE, while no such effect was seen during solar maximum.
\end{abstract}

Subject headings: Sun: prominences — Sun: filaments — Sun: coronal mass ejections — Sun: radio radiation — Sun: corona

\footnotetext{
${ }^{1}$ Laboratory for Extraterrestrial Physics, NASA Goddard Space Flight Center, Greenbelt, MD 20771

${ }^{2}$ Nobeyama Radio Observatory, Nagano 384-1305, Japan

${ }^{3}$ The Catholic University of America, Washington DC 20064

${ }^{4}$ Naval Research Laboratory, Washington, DC
} 
This is an unedited preprint of an article accepted for publication in Astrophysical Journal. The final published article may differ from this preprint.

Copyright 2002 by The American Astronomical Society. Please cite as 'ApJ preprint doi:10.1086/367614'.

\section{Introduction}

Prominence eruptions are one of the earliest known forms of mass ejections from the Sun and have received considerable attention since the late 1800's (see, e.g., TandbergHanssen,1995, for a historical introduction on prominences and their dynamics). Two primary types of mass motions have been recognized in prominences, one with material streaming from one part of the solar surface to another ("active prominences") and the other with prominence material leaving the Sun partially or completely ("eruptive prominences"). A detailed study of these "moving" prominences (de Jager, 1959) is important for a clear understanding of coronal mass ejections (CMEs) because we know now that the inner core of CMEs is made up of prominence material (see, e. g., House et al., 1981).

It was also recognized early on that prominence eruptions is the near-surface activity most frequently associated with CMEs (Webb et al., 1976; Munro et al., 1979; Webb and Hundhausen, 1987; St Cyr and Webb, 1991). Works on CMEs often treated the prominence eruption as a secondary process during the CME phenomenon because prominence may not have enough energy to drive CMEs (Hundhausen, 1999; Smith et al., 1992). However, there are alternative viewpoints suggesting a primary role for the prominences: Filippov (1998) has shown that CMEs can be caused by the eruption of inverse-polarity prominences. Therefore, it is important to start from prominence eruptions and study their association with CMEs. Coronagraphs require an occulting disk in order to block the photospheric light so that the corona can be observed. This makes it difficult to observe the very early phase of CMEs when they are below the occulting disk. Therefore, observing prominence eruptions close to the surface helps us learn about the earliest phase of the eruption. In an early study, Webb et al., (1976) found that all filament disappearances they examined had a "transient coronal manifestation." Munro et al. (1979) studied the association between eruptive prominences at limb (EPL) and CMEs. They used reports of H-alpha EPL and found that the maximum height reached by the prominence is an important parameter in deciding whether it is associated with a CME. These authors found that virtually all prominences that attained a height of at least $1.2 \mathrm{R}_{\odot}$ were associated with CMEs observed by the ATM coronagraph on board Skylab.

Prominence eruptions have traditionally been observed in the H-alpha line. After the advent of the Nobeyama radioheliograph (NoRH, Nakajima et al., 1994), synthesis imaging in microwaves has proved to be an important source of information on prominence eruptions (Hanaoka et al., 1994), especially for studying the relationship between prominence eruptions and CMEs (Gopalswamy et al., 1996; 1997; 1998). Prominences contain cool material ( $8000 \mathrm{~K}$ ) and hence are optically thick in microwaves (Gopalswamy, 1999). The thermal free-free emission from the prominence plasma happens to be the dominant emission in 
This is an unedited preprint of an article accepted for publication in Astrophysical Journal. The final published article may differ from this preprint.

Copyright 2002 by The American Astronomical Society. Please cite as 'ApJ preprint doi:10.1086/367614'.

microwaves outside the solar disk and hence can be imaged with great clarity. The free-free radiation is a continuum emission so the prominence can be tracked even when it is heated to a higher temperatures (Heated prominences will disappear in H-alpha).

Case studies have shown that eruptive prominences can be traced into the inner parts of as the bright core (House et al. 1981; Gopalswamy et al., 1998; Gopalswamy, 1999), as expected from the study of Munro et al. (1979). However, in 1997, there was a suggestion from the Big Bear Solar Observatory data that the association between H-alpha prominence eruptions and white-light coronal mass ejections was rather poor (Wang and Goode, 1998) and this suggestion was questioned by the present lead author and O. White (see the Group Discussion section of Wang and Goode, 1998). Subsequently, Gilbert et al. (2000) studied the CME association of a set of H-alpha prominence eruptions, and found that $92 \%$ of the eruptive prominences and $46 \%$ of the active prominences were associated with CMEs, thus confirming the original conclusion by Munro et al. (1979). Hori and Culhane (2002) found similar relationship between 50 microwave prominence eruptions observed by NoRH and white-light CMEs with a slightly better association (94\%). Recently, Yang and Wang (2002) reported the results of a statistical study of a large number of prominence and filament eruptions (431 in all) with the conclusion that only 10 to $30 \%$ of the prominence eruptions were associated with CMEs, which is consistent with the earlier BBSO study (Wang and Goode, 1998). We were puzzled by this result and decided to revisit this issue by analyzing a large number of prominence eruption events detected automatically in the NoRH 10 min images. In addition, we examined the statistical properties and solar cycle variation of the prominence eruptions.

\section{Data Selection}

Although NoRH observes both filaments and prominences, we have chosen only the prominences because we can easily measure the height-time characteristics of the latter. NoRH observes the Sun at 17 and $34 \mathrm{GHz}$ between 22:30 UT and 06:30 UT, thus providing high quality data for up to 8 hours per day with little interruption due to weather conditions. The microwave images have a spatial resolution of $\sim 15$ and 8 arc sec at $17 \mathrm{GHz}$ and $34 \mathrm{GHz}$ respectively. We use only the $17 \mathrm{GHz}$ images archived at the Nobeyama Radio Observatory for this study. The starting point of this study is the set of all limb events automatically detected using the NoRH images synthesized every 10 minutes ( 44 images per day). We considered all the prominence eruption events from January 1, 1996 to December 31, 2001, covering the minimum to the maximum periods of the current solar cycle 23. 
This is an unedited preprint of an article accepted for publication in Astrophysical Journal. The final published article may differ from this preprint.

Copyright 2002 by The American Astronomical Society. Please cite as 'ApJ preprint doi:10.1086/367614'.

\subsection{Selection Criteria}

The corona is optically thin at microwave frequencies, so it contributes very little to the observed brightness temperature $(\mathrm{Tb})$. On the other hand, Prominences are optically thick objects at microwave frequencies, so the observed brightness temperature $(\mathrm{Tb})$ is typically the kinetic temperature $(\sim 8000 \mathrm{~K})$ of the prominence plasma. Therefore the prominence appears as a bright feature against the cold sky. The observability of prominences is limited by the dynamic range of the radio images, which is typically $\sim 100$. The solar disk at 17 $\mathrm{GHz}$ has a $\mathrm{Tb}$ of about 10,000 K. Active regions (nonflaring) may also be present on the disk with a $\mathrm{Tb}$ of tens of thousands $\mathrm{K}$. Therefore, we decided to identify all the prominences that had a $\mathrm{Tb}$ of at least $2000 \mathrm{~K}$ or $1 / 100$ of the maximum $\mathrm{Tb}$ in each image.

The automatic detection program finds enhanced pixels in each image outside the solar disk. A pixel is considered enhanced when its $\mathrm{Tb}$ exceeds 6 times the average $\mathrm{Tb}$ of the day at that pixel. If there is a group of enhanced pixels in the images, the center of mass of the enhanced pixels is calculated and tracked in time. If the center of mass changes its location between successive frames, and is persistent in at least 3 consecutive images, the program defines the structure as a prominence event (provided the centroid does not fall on the disk).

This procedure obviously cannot detect those prominences, which spend less than 30 min within the NoRH field of view (FOV). This means some of the fast events that quickly cross the FOV and those occurring close to the boundaries of the Nobeyama daytime may not be detected. One of the quantities used by the automatic detection program is the whole-day average of the $\mathrm{Tb}$. If a prominence is too slow $\left(<\mathrm{a}\right.$ few $\mathrm{km} \mathrm{s}^{-1}$ ), the program may not detect it since the structure increases the average $\mathrm{Tb}$ of the day. If two eruptive events occur above opposite hemispheres simultaneously, the center of mass of the enhanced

pixels would fall on the disk and so the program would not detect such eruptions. With these criteria, 226 limb events were automatically detected between January 1996 and December 2001.

\subsection{White-Light Data}

White-light data corresponding to the prominence events were obtained by the Solar and Heliospheric Observatory (SOHO) mission's Large Angle and Spectrometric Coronagraph (LASCO, Brueckner et al., 1995), which continuously images the solar corona up to an unprecedented heliocentric distance of $\sim 30 \mathrm{R}_{\odot}$ using its two telescopes $\mathrm{C} 2$ and $\mathrm{C} 3$. There was a major data gap in 1998 (June to October) when SOHO was temporarily disabled. There were also additional data gaps up to a maximum of 1 month during the later period. 
This is an unedited preprint of an article accepted for publication in Astrophysical Journal. The final published article may differ from this preprint.

Copyright 2002 by The American Astronomical Society. Please cite as 'ApJ preprint doi:10.1086/367614'.

We excluded those prominence events that occurred during the LASCO data gaps. This reduced the list to 186 events, which we analyze in this paper.

\section{Statistical Properties of Prominence Events}

We re-imaged all the identified prominence events with a cadence of 2 minutes in order to study the height-time history of the events. We also shifted the image center to the initial location of the prominence, so that it could be tracked for more than one solar radius from the limb (the NoRH FOV is 40 arc min). The data analysis is based on two aspects of the data set. (i) Examination of the prominence movies, and (ii) height-time measurements. The movies helped us identify the predominant direction of motion of the prominence, while the height-time measurements helped us obtain quantitative information on the prominence motions.

\subsection{Prominence Trajectories: Radial and Transverse Events}

The automatic program can detect not only prominence eruptions but also prominence activities and limb flares because it does not check the direction and speed of the prominence motion. Therefore, we refer to all the events detected automatically as "Prominence Events (PEs)." By playing movies of the NoRH images, we identified two predominant types of motions in the prominences. A vast majority of the prominences moved out radially from their initial location, which eventually did one of the following: (1) the prominence continued to move beyond the NoRH FOV, (2) faded before reaching the edge of the NoRH FOV the field of view, and (3) part of the prominence fell back to the solar surface. When the prominence had a significant motion in the radial direction, we refer to it as a radial $(\mathrm{R})$ event. In a minority of the PEs, the motion was predominantly horizontal (parallel to the limb) with or without a change in height. The horizontal motions appeared as blobs moving from one position angle (PA) to another, whip-like motion with a detachment only at one leg or the whole prominence moving parallel to the limb. We refer to these as transverse (T) events. According to the traditional definition of prominence motions, the $\mathrm{R}$ and $\mathrm{T}$ events would roughly correspond to the "eruptive" and "active" prominences, respectively.

Figure 1 shows various types of trajectories that can be identified in our sample. Constant-speed (Fig.1a), accelerating (Fig. 1b), and decelerating (Fig. 1c) profiles were found, somewhat similar to the profiles of white light CMEs (Gopalswamy et al., 2001). In Fig. 2, we have shown the trajectories of all the PEs for which height-time measurements 
This is an unedited preprint of an article accepted for publication in Astrophysical Journal. The final published article may differ from this preprint.

Copyright 2002 by The American Astronomical Society. Please cite as 'ApJ preprint doi:10.1086/367614'.

could be made. In Fig. 2(a) we have shown the complete trajectories (from the onset of eruption to the end or until the prominence left the NoRH FOV). In Fig. 2(b) we have

shown only the upward portion of the trajectories. One can see two populations of PEs: one with little change in height with time and the other with clear increase at least initially. It turns out that the two populations correspond to the $\mathrm{R}$ and $\mathrm{T}$ events defined above (see Fig. $2 \mathrm{c}, \mathrm{d})$.

\subsection{Prominence Heights}

As Fig. 2 indicates, prominences attained various final heights within the NoRH FOV. Some events faded with no apparent change in the trajectory within the NoRH FOV and could not be tracked to larger heights. Many prominences continued beyond the NoRH FOV. For those PEs which had trajectories similar to Fig. 1c, we can define a maximum height. This is true for most of the $\mathrm{T}$ events because the maximum height attained is very small. Therefore one can define a characteristic height as the maximum height to which a prominence can be tracked. For the $\mathrm{T}$ events, this is a true maximum height. For the $\mathrm{R}$ events, this is a lower limit to the actual height attained by the prominence. For those events which escape the solar gravity, one cannot define a maximum height because the prominences eventually become part of the solar wind. In a few events that started just before the beginning of observations, the prominences were observed to fall to the solar surface from a large initial height; we take this initial height as the characteristic height. For some others we could not get the complete height-time history because the observations ended when the eruption was in progress; for these, we assumed the last observed height to be the final height.

The distribution of final heights is shown in Fig. 3. The representative heights ranged from .05 to $2.5 \mathrm{R}_{\odot}$. These are heights projected in the sky plane, so the actual heights may be greater, depending on where the prominence originated from. The average of the distribution for all PEs is $1.35 \mathrm{R}_{\odot}$. We have compared the distribution of the final heights of the general population with that of the $R$ and $T$ populations. We recognize that the average final height of the $\mathrm{R}$ events $\left(1.39 \mathrm{R}_{\odot}\right)$ is significantly larger than that $\left(1.15 \mathrm{R}_{\odot}\right)$ of the $\mathrm{T}$ events. Moreover, none of the $\mathrm{T}$ events were seen beyond $1.25 \mathrm{R}_{\odot}$. The height attained by the prominence seems to be a clear distinguishing parameter between $\mathrm{R}$ and $\mathrm{T}$ events. 
This is an unedited preprint of an article accepted for publication in Astrophysical Journal. The final published article may differ from this preprint.

Copyright 2002 by The American Astronomical Society. Please cite as 'ApJ preprint doi:10.1086/367614'.

\subsection{Prominence Velocities}

As was seen in Fig. 1, the eruptive prominences showed acceleration, deceleration or constant speed within the NoRH field of view. In order to assign a speed to each of the prominences, we computed the average speed by fitting a straight line to the data points on the rising segment of the height-time plots. This eliminated 6 events with negative speed (falling from a large height due to onset of the eruption before the beginning of the observations). For 8 of the $\mathrm{T}$ events, it was not possible to obtain a meaningful outward velocity. The distribution of speeds of the remaining 174 events is shown in Fig. 4(a). The speed ranges from a few $\mathrm{km} \mathrm{s}^{-1}$ to $400 \mathrm{~km} \mathrm{~s}^{-1}$. The speeds of $\mathrm{R}$ and $\mathrm{T}$ events are also shown in Fig. 4(b,c). The average speed of the $\mathrm{R}$ events $\left(65 \mathrm{~km} \mathrm{~s}^{-1}\right)$ is closer to that of the general population $\left(57 \mathrm{~km} \mathrm{~s}^{-1}\right)$; the average speed of the $\mathrm{T}$ events $\left(10 \mathrm{~km} \mathrm{~s}^{-1}\right)$ is much smaller than that of the general population. The maximum speed attained by the prominences within the NoRH FOV is only $\sim 400 \mathrm{~km} \mathrm{~s}^{-1}$, much smaller than the escape velocity at the solar surface $\left(620 \mathrm{~km} \mathrm{~s}^{-1}\right)$, but comparable to the escape velocity at $2.5 \mathrm{R}_{\odot}$.

Figure 5 is a scatter-plot between the final height reached by the prominences and the average speed during the rise phase. There is a clear trend of faster prominences reaching greater heights (the correlation coefficient is 0.62). Munro et al. (1979) had speculated that prominences reaching a larger height may have larger initial energy. We are able to confirm this result because we have velocity measurements for the prominences.

\section{Relation between CMEs and Prominence Eruptions}

We chose the beginning of our study period to coincide with the time when SOHO started accumulating data on CMEs in early 1996 (close to the beginning of cycle 23). The study period ends near the maximum of solar cycle 23. Thus we have the unique opportunity to study the association between prominence eruptions and CMEs from the minimum to the maximum phase of the solar cycle. Since we know the precise location of the prominence on the limb, it is rather a simple matter to look for CMEs around the position angle (PA) of the prominence. Both radio and white-light data could be viewed as movies, which greatly helped establishing the position angle and temporal correspondence between prominence eruptions and CMEs. Once we identified the CME, we collected all the standard properties (speed, width, central position angle (CPA), and the time of first appearance in the C2 FOV) of the CMEs from the SOHO/LASCO CME catalog (http://cdaw.gsfc.nasa.gov/CME_list). We also determined the approximate onset times of CMEs by extrapolating the height-time plot to the solar surface, without accounting for the projection effects. 
This is an unedited preprint of an article accepted for publication in Astrophysical Journal. The final published article may differ from this preprint.

Copyright 2002 by The American Astronomical Society. Please cite as 'ApJ preprint doi:10.1086/367614'.

Table 1 compares the measured properties of the prominence eruptions and those of the associated CMEs. The table actually lists all the prominence events with their date, time, position angle, speed, final height, and the event type (radial or transverse) in columns 2-7, in that order. In Columns 8-11 we have given the CME time, position angle, width, and speed. In the last column, we have stated whether the associated CME has a core feature or not ( $\mathrm{Y}=$ yes; $\mathrm{N}=\mathrm{no}$ ). In the CME time column (8), $\mathrm{N}$ denotes the absence of a CME and $\mathrm{S}$ denotes that the prominence event was associated with a streamer change (see below).

Before going into the statistical associations, we illustrate the CME-prominence relationship using two examples, one with and the other without association. One of the spectacular eruptive prominences (2000 October 22) is shown in Fig. 7. The prominence rose slowly from an initial height of $1.3 \mathrm{R}_{\odot}$ and accelerated $\left(61 \mathrm{~m} \mathrm{~s}^{-2}\right)$ to attain a speed of $\sim 150 \mathrm{~km} \mathrm{~s}^{-1}$ by the time it faded at a height of $\sim 2.4 \mathrm{R}_{\odot}$. Figure $7(\mathrm{e}-\mathrm{h})$ shows the corresponding white light CME observed by SOHO/LASCO. This was a streamer blowout event as can be seen in Fig. 7(e-h). The white light CME was very fast $\left(1024 \mathrm{~km} \mathrm{~s}^{-1}\right)$ and showed slight deceleration within LASCO field of view. However, when we used the C2 data alone, the CME showed a clear acceleration, consistent with the prominence height-time profile.

Figure 8 shows the 2001 August 29 prominence eruption from above the south east limb. It is a well observed event with an initial height of $1.15 \mathrm{R}_{\odot}$ and moving to a final height of only $1.25 \mathrm{R}_{\odot}$. The southern leg of the prominence disappears during the eruption and the predominant motion seems to be transverse, towards the equator. This is one of the ambiguous events that could be classified as an $\mathrm{R}$ or $\mathrm{T}$ events. We decided to classify this as an $\mathrm{R}$ event from the initial motion. The SOHO/LASCO difference images show that there is no discernible change around the CPA of the eruptive prominence.

An event-by-event comparison between the radio and white light data revealed that 134 of the 186 prominence events were associated with CMEs. Among the remaining events, 34 had no associated CMEs at all and 11 had obvious streamer changes. The streamer changes are discussed below in a separate subsection. The CME-associated prominence events were generally faster and attained larger heights, as summarized in Table 2. Histograms of the heights of PEs with and without CMEs are shown in Fig. 6. The distribution of the final heights for the CME-related PEs is remarkably similar to that of the $\mathrm{R}$ events in Fig. 3 . The same holds for the PEs without CMEs and the $\mathrm{T}$ events in Fig. 3. Prominences reaching larger heights are clearly associated with CMEs. 
This is an unedited preprint of an article accepted for publication in Astrophysical Journal. The final published article may differ from this preprint.

Copyright 2002 by The American Astronomical Society. Please cite as 'ApJ preprint doi:10.1086/367614'.

\subsection{Source Latitudes}

We converted the observed CPA of the PEs and CMEs events to heliographic latitudes by assuming that the events happen in the plane of the sky. For example, a prominence eruption from $\mathrm{PA}=90^{\circ}$ or $270^{\circ}$ will be considered to have a zero latitude; from $\mathrm{PA}=135^{\circ}$ or $225^{\circ}$ will be considered to be originating from a latitude of - $45^{\circ}$ (South $45^{\circ}$ ) and so on. Fig. 9 shows the latitude distributions of all the prominences along with those of the associated CMEs. We note that the latitude distribution of the prominence events shows two peaks corresponding to the active latitudes, although events could be found from almost all latitudes. There were only three events from close to equator. The latitude distribution of the CMEs does not show the double peak. Instead, we see only one broad peak centered on the equator. In fact the largest bin in the CME latitude distribution corresponds to zero latitude. However, as in the case of prominence eruptions, CMEs originate from almost all latitudes.

In order to see the solar cycle variation of the source latitudes of CMEs and PEs, we have plotted them as a function of time in Fig 10. Clearly, the spreading to higher latitudes occurs at different rates for prominences and CMEs close to the minimum and rising phases, while they are quite similar during the maximum phase. The rapid increase of the source latitudes of CMEs and PEs towards the end of 1999 roughly coincides with the approach to the maximum tilt angle of the heliospheric current sheet (see, e.g., Cliver \& Ling, 2001). It is known for a long time that the prominences occur at all latitudes during solar maxima (see, e.g., Ananthakrishnan, 1961; Hundhausen 1999). The reason for the CPA of CMEs to be close to the equator during solar minimum can be explained by the strong influence of the large-scale field on the prominences as evidenced by the non-radial motion of prominences (Gopalswamy, Hanaoka and Hudson, 2000; Filippov, Gopalswamy and Lozhechkin, 2001). The typical scenario is that the prominence originates from the active region belt and moves towards the equator, while the overlying field lines, which become the CME frontal structure, span the equator and hence appear at a very small CPA.

\subsection{Timing Relationship between CMEs and Prominence Events}

We have compared the onset times of PEs and the associated CMEs in Fig. 11a, which is a histogram of the difference between the two onset times. We had to eliminate some events with negative speeds because we do not know their actual onset times. The prominence onset times were directly obtained from the start times of the prominence events. For CMEs, we extrapolated the height-time plots to $1 \mathrm{R}_{\odot}$, assuming constant speed. Of course we know that this is not a good assumption because most of the prominence-related CMEs 
This is an unedited preprint of an article accepted for publication in Astrophysical Journal. The final published article may differ from this preprint.

Copyright 2002 by The American Astronomical Society. Please cite as 'ApJ preprint doi:10.1086/367614'.

show large accelerations initially. Acceleration would move the onset to earlier times. On the other hand, extrapolation of the height-time plots to $1 \mathrm{R}_{\odot}$ may not be quite correct because CMEs may erupt from a pre-eruption height, which would move the onset to later times. It is well known that the helmet part of the pre-eruption streamer structures often stand at a height of $2 \mathrm{R}_{\odot}$. Thus the two factors have opposite tendencies and make the linear extrapolation closer to reality. Projection effects may also introduce some uncertainty in the onset times. With these cautionary notes, we recognize that the onset times of the prominence events and CMEs are roughly the same, within $+/-0.5 \mathrm{hr}$. This seems to be true independent of the phase of the solar cycle, as is clear from Fig. 11b. The tight relationship between the two onsets is consistent with the recent model by Low and Zhang (2002), which requires the removal of prominence material to initiate the release of CME flux ropes.

\subsection{Spatial Relationship between CMEs and Prominence Events}

We studied the spatial relationship between the PEs and CMEs by comparing their latitudes. The latitudes were obtained simply from the PAs as before. Since we are interested in the latitude offsets of PEs and CMEs, we computed them from the absolute values of the latitudes (i.e., we did not care about the hemisphere of origin). Fig. 12 (a) shows the difference in the prominence and CME latitudes as a histogram. Positive values mean that the prominences are at higher latitudes than the CMEs and vice versa. Note that there are more events with positive offsets. This is clearly the same result presented differently in Fig. 9. This means that the latitude of CMEs is closer to the equator than that of corresponding prominence irrespective of the hemisphere. To see if this effect persists with time, we have shown the latitude offset as a function of time in Fig. 12 (b). Note that up to the end of 1999, the CME latitudes are clearly offset towards the equator. Beyond that time, there is no systematic offset. This can be explained as the effect of the solar dipolar field which is stronger during the solar minimum resulting in a prominent equatorial streamer belt while the streamers can be found in all latitudes during the solar maximum.

\subsection{Core Association}

The primary connection between white-light CMEs and prominence eruptions is through the CME core. The white-light core has been shown to be the expanded version of the prominence observed in H-alpha (House et al., 1981) or microwaves (Gopalswamy et. al., 1996; Gopalswamy, 1999) closer to the surface. In order to illustrate this connection, we have shown the 2001 December 19-20 event in Fig 13. In the top row, we have shown the prominence 
This is an unedited preprint of an article accepted for publication in Astrophysical Journal. The final published article may differ from this preprint.

Copyright 2002 by The American Astronomical Society. Please cite as 'ApJ preprint doi:10.1086/367614'.

eruption in microwaves. The prominence actually originated from the southwest quadrant

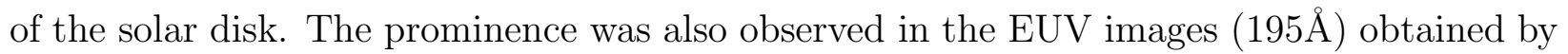
SOHO's Extreme-ultraviolet imaging telescope (EIT, Delaboudinière et al., 1995), as shown in the middle panels. A post-eruption arcade flanked by coronal dimming can also be seen in the EUV images. The white light CME in the bottom panel has the classical three-part structure. Both the images and the height-time plot (Fig. 13m) show that the eruptive prominence observed in microwaves and EUV becomes the core of the CME observed in white light. The height-time behavior is similar to the one reported by Gopalswamy et al. (1998).

We examined the internal structure of all the CMEs in our data set and compared the white-light cores with the corresponding microwave prominences. We found that out of the 134 CMEs identified to be associated with the prominence events, 98 (73\%) had clear whitelight cores. This rate is slightly higher than the $65 \%$ reported by Hori and Culhane (2002). In Fig. 14 we have compared the speed distribution of the $98 \mathrm{CMEs}$, their cores and the microwave prominence events. In Fig. 15 we have shown the correlation between the core speeds and prominence speeds for the 98 events. While there is a trend of fast prominence events associated with faster white light cores, the correlation is weak. This is probably due to the different spatial domains in which the prominence is measured between which it evolves rapidly due to heating and expansion. Clearly, the core speed is always greater than the prominence speed (as evidenced by the equal-speed line in Fig. 15), consistent with the fact that most prominences accelerate to larger speeds at greater heights.

\subsection{Streamer Events}

A closer examination of the white light images corresponding to the prominence events with no associated CMEs revealed that a number of them $(11 / 52=21 \%)$ were associated with a change in the overlying white-light streamers. The average final height of the "streamer events" is $1.19 \mathrm{R}_{\odot}$, intermediate between those of the $\mathrm{R}$ and $\mathrm{T}$ events. Their average speed $\left(13 \mathrm{~km} \mathrm{~s}^{-1}\right)$ is more than that of the $\mathrm{T}$ events $\left(10 \mathrm{~km} \mathrm{~s}^{-1}\right)$, but well below the average speed of the $\mathrm{R}$ events $\left(65 \mathrm{~km} \mathrm{~s}^{-1}\right)$. As one would expect, a majority $(7 / 11=74 \%)$ of the streamer distention events were $\mathrm{T}$ events while the remaining $(4 / 11=36 \%)$ were low-height R events. Typically, the change was either a weak flow in the streamer or a slight distention. Fig. 16a-d shows the 1998 June 1 prominence event along with the height-time plot. The prominence moved radially outward, but only slightly from an initial height of about 1.24 $\mathrm{R}_{\odot}$ to a final height of $1.28 \mathrm{R}_{\odot}$ and then stalled. The average radial speed was only about $8 \mathrm{~km} \mathrm{~s}^{-1}$. Fig. 16e-h shows the corresponding white light images. Note that the streamer 
This is an unedited preprint of an article accepted for publication in Astrophysical Journal. The final published article may differ from this preprint.

Copyright 2002 by The American Astronomical Society. Please cite as 'ApJ preprint doi:10.1086/367614'.

slowly expanded around the time of the prominence event. The streamer was actually blown off the next day and the resulting CME contained one of the most spectacular prominence cores (Plunkett et al., 2000).

\section{Discussions}

Munro et al. (1979) recognized that the prominence height is an important parameter that decides the association between prominence eruptions and CMEs: the larger the height attained by the prominences, the better was their association with CMEs. They concluded that all eruptive prominences at limb (EPL) observed beyond a height of $1.2 \mathrm{R}_{\odot}$ and only $60 \%$ of those observed beyond a height of $1.1 \mathrm{R}_{\odot}$ were associated with CMEs. They also noted that two-thirds of the reported eruptive prominences are never observed beyond a height of $1.1 \mathrm{R}_{\odot}$ and that fewer than $10 \%$ of these were associated with CMEs. Although Munro et al. (1979) did not discuss the direction of predominant motion of the prominences, we see that their low maximum height events are similar to our T events. Munro et al. had also speculated that if the observed maximum height is an indicator of the energy content of the prominence eruption, then CMEs are associated with more energetic prominence eruptions. Since we were able to measure the height-time history of the prominences, we were able to obtain their speeds. The good correlation between the observed final height and the average prominence speed (see Fig. 5) found in this paper supports suggestion by Munro et al. (1979).

The $\mathrm{R}$ and $\mathrm{T}$ prominence events discussed in this paper are somewhat similar to the traditional definition of eruptive and active prominences, with a primary emphasis on the direction of motion. The H-alpha prominence eruptions discussed by Gilbert et al. (2000) were also classified as eruptive and active, which correspond to our R and T events, respectively. Even though Gilbert et al. had a small sample it is worthwhile to compare our results with theirs because they also used SOHO/LASCO data. While the final heights and speeds are comparable, the CME associations are significantly different especially for the T events. Gilbert et al. found that nearly every other (46\%) active prominence event was associated with CMEs, while our T events had a much poorer (24\%) association with CMEs. It is not clear if this is due to sample size. Our $\mathrm{R}$ events had also a slightly poorer CME association (84\% compared to Gilbert et al.'s 94\%).

The selection criteria employed by Hori and Culhane (2002) are different from ours, so we expect to have different results: 1) They considered only prominence eruptions from close to the solar maximum (February 1999 to May 2000). 2) They also required that NoRH, SOHO/LASCO and Yohkoh/SXT observe the eruptions from the start. 3) They also 
This is an unedited preprint of an article accepted for publication in Astrophysical Journal. The final published article may differ from this preprint.

Copyright 2002 by The American Astronomical Society. Please cite as 'ApJ preprint doi:10.1086/367614'.

included eruptions that could be classified as sprays and surges. 4) The associated CMEs were identified using synoptic maps constructed from the limb data at 2.5, 3.5, and $4.5 \mathrm{R}_{\odot}$, rather than from the direct images. In this way, they selected 50 prominence eruptions and found that $92 \%$ were associated with white-light CMEs. Over the study period of Hori and Culhane, we identified 62 prominence eruptions using the automatic detection program, out of which $47(76 \%)$ were associated with CMEs, a result similar to that from the extended sample of the present study. We must point out that only 30 of the 50 events in Hori and Culhane (2002) overlapped with our list. Thus selection criteria seem to have influenced the relation between prominence eruptions and CMEs. As for the core association, Hori and Culhane found that only about $60 \%$ of the prominence related CMEs had white-light cores, while our rate was higher $(73 \%)$.

Yang and Wang (2002) studied the association between 431 prominence events and the associated CMEs and noted that "the association of filament disappearances and CMEs is very low, ranging between 10 to 30\%." They considered both prominence and filament disappearances that occurred during February 1997 to June 1999. They also grouped the eruptive events according to their central meridian distance. It is appropriate to consider the group corresponding to a central meridian distance of 0.9 to $1 \mathrm{R}_{\odot}$ to compare with our events. From Figure 1 of Yang and Wang (2002), we found that 50 eruptions could be considered as limb events. Only 18/50 (=36\%) of these prominence eruption events were associated with white-light CMEs observed by SOHO/LASCO. This rate is clearly half of what we found for the extended sample of radio prominence eruption events studied in the present work. Yang and Wang suggested the following reasons for the poor association: (1) they did not distinguish between thermal disappearance and true eruption of filaments; (2) they might have missed weak halo CME events associated with the disk events; (3) some events may have had speeds less than the escape speed of the Sun with prominence material falling back to the solar surface. We do not know what fraction of their events may be thermal disappearances. Reason (2) is not applicable to their limb events, because, LASCO can see most of the CMEs originating from the limb. Reason (3) is not convincing because most prominence eruptions have speeds less than the escape speed close to the Sun (see Fig. 4). Thus, there seems to be no convincing explanation for the poor association between PEs and CMEs.

For a consistency check, we counted the subset of prominence eruptions in our sample corresponding to the study period (February 1997 to July 1999) of Yang and Wang and found 63 events that overlapped with $\mathrm{SOHO} / \mathrm{LASCO}$ data. When we checked the LASCO data, we found that $41 / 63(=65 \%)$ of these radio prominence eruptions were associated with LASCO CMEs. This number is not too different from the $72 \%$ we obtained for the entire sample of this study, and is nowhere near the 36\% reported by Yang and Wang (2002). Puzzled 
This is an unedited preprint of an article accepted for publication in Astrophysical Journal. The final published article may differ from this preprint.

Copyright 2002 by The American Astronomical Society. Please cite as 'ApJ preprint doi:10.1086/367614'.

by this, we further examined the 26 large events (filament length $>\sim 250$ arc sec) listed in their Table I, out of which only $11 / 26(=42 \%)$ were reported to have CME association. However, 9 of the 26 filament eruption events occurred during major SOHO data gaps (June - October 1998 and January, 1999). It is not clear if they checked other CME data sources such as from the ground based Mauna Loa K-Coronameter. If we exclude the 9 events from the sample, then we see that $11 / 17(=65 \%)$ of the BBSO filament eruption events were associated with CMEs, consistent with the microwave prominence eruption results. If they did not account for the SOHO data gaps, then similar discrepancy may result for the entire sample of 431 BBSO events. If the data gap is not the main problem, one has to look for other reasons to explain the poor association. One possibility is that Yang and Wang (2002) and Wang and Goode (1998) might have preferentially identified the low maximum height $(<1.1 \mathrm{R} \odot)$ prominence eruptions, because the height attained by the prominence is an important parameter that decides the association.

\section{Summary and Conclusions}

We studied the height-time history and CME association of all the prominence events automatically detected by the Nobeyama radioheliograph. Out of the 226 events identified between January 1996 and December 2001, 186 had simultaneous CME data coverage from the SOHO mission. From height-time plots we were able to classify the prominence events into two groups: Radial events that had motion predominantly in the radial direction and transverse events that had motion roughly parallel to the limb. Radial events attained larger heights and had greater average speeds as compared to the transverse events. We identify the radial and transverse events with the classical eruptive and active prominence events, respectively. The radial events showed close relationship to the CMEs. We found that $72 \%$ of all the prominence events and $83 \%$ of the radial events were associated with CMEs. Thus, we have confirmed the close relationship between prominence events and CMEs using a large sample of microwave prominences. This result is consistent with three previous studies (Munro et al., 1979; Gilbert et al., 2000, and Hori and Culhane, 2002) that used smaller sample sizes. However, our results contradict those of Wang and Goode (1998) and Yang and Wang (2002) who reported a poor association between prominence eruptions and CMEs. Our result that $73 \%$ of the prominence events are associated with CMEs, is twice larger than the $36 \%$ association found for BBSO H-alpha eruptions (Yang \& Wang, 2002). Prominence eruptions without CMEs are very slow and are restricted to regions close to the solar surface. These events are generally the transverse events.

We also studied the spatial and temporal relationship between the prominence events 
This is an unedited preprint of an article accepted for publication in Astrophysical Journal. The final published article may differ from this preprint.

Copyright 2002 by The American Astronomical Society. Please cite as 'ApJ preprint doi:10.1086/367614'.

and the corresponding CME events. We found that the onsets of prominence events and CMEs were nearly simultaneous, within $\sim 30 \mathrm{~min}$. This result may have important implications to the theories of CME initiation. We also confirmed the spreading of the source locations of CMEs and prominences to all latitudes towards the solar maximum. However, the central position angles of CMEs and prominence events generally did not coincide. During solar minimum, the central position angles of CMEs tend to cluster around the equator, while those of the prominence events were confined to the latitudes of active region belt. During solar maximum, there is no such relationship, reflecting the varied influence of the solar dipolar field on CMEs during solar minimum and maximum.

We thank Steve Nunes for reading the manuscript. The research of SY and WL were supported by NASA and Air Force Office of Sponsored Research (F49620-00-1-0012). SOHO is a project of international cooperation between ESA and NASA. NG thanks the Nobeyama Radioheliograph group for hospitality during his visit in February 2002, when part of this work was done.

\section{REFERENCES}

Ananthakrishnan, R. 1961, ApJ, 133, 969

Brueckner, G. E. et al. 1995, Sol. Phys., 162, 357

Cliver, E. W. \& Ling, A. G. 2001, ApJ, 551, L189

De Jager, C. 1959, Handbuch der Physik, 52, 80

Delaboudinière et al, 1995, Sol. Phys., 162, 291.

Filippov, B. P. 1998, in New Perspectives on Solar Prominences (IAU Colloquium 167), ed. D. Rust, D. F. Webb, and B. Schmieder, Vol. 150, p. 342

Filippov, B. P., Gopalswamy, N., \& Lozhechkin, A. V. 2001, Sol. Phys., 203, 119

Gilbert, H. R., Holzer, T. E., Burkepile, J. T., and Hundhausen, A. J. 2000, ApJ, 537, 503.

Gopalswamy, N. 1999, Proceedings of the Nobeyama Symposium, held in Kiyosato, Japan, Oct. 27-30, 1998, Eds.: T. S. Bastian, N. Gopalswamy and K. Shibasaki, NRO Report No. 479., p.141

Gopalswamy, N., Kundu, M. R., Hanaoka, Y., Enome, S., and Lemen, J. R. 1996, New Astronomy, 1, 207. 
This is an unedited preprint of an article accepted for publication in Astrophysical Journal. The final published article may differ from this preprint.

Copyright 2002 by The American Astronomical Society. Please cite as 'ApJ preprint doi:10.1086/367614'.

Gopalswamy, N., Hanaoka, Y., Kundu, M. R., Enome, S., Lemen, J. R., Akioka, M., Lara, A., 1997, ApJ, 475, 348.

Gopalswamy, N., \& Hanaoka, Y, 1998, ApJ, 498, L179.

Gopalswamy, N., Hanaoka, Y., and Hudson, H. S. 2000, AdSpR, 25, 1851.

Gopalswamy, N., Yashiro, S., Kaiser, M. L., Howard, R. A., \& Bougeret, J.-L. 2001, J. Geophys. Res., 106, 29219

Hanaoka et al., 1994, PASJ, 46, 205

Hori, K. \& Culhane, J. L. 2002, A\&A, 382, 666.

House, L. L., Wagner, W. J., Hildner, E., Sawyer, C., and Schmidt, H. U. 1981, ApJ, 244, L117

Hundhausen, A. J. 1988, in Proc. Sixth international Solar Wind Conference, Vol. 1, ed. V. J. Pizzo, T. E. Holzer, and D. G. Sime, High Altitude Observatory, NCAR, Boulder, Colorado, p. 181

Hundhausen, A. J. 1999, Many Faces of the Sun, ed. K. T. Strong, J. L. R. Saba, and B. M. Haisch, Springer-Verlag, New York, p. 143

Low, B. C. and Zhang, M., 2002, ApJ, 564, L53

Munro, R. H. et al. 1979, Sol. Phys., 61, 201

Nakajima et al., 1994, Proc. IEEE, 82, 705

Plunkett et al., 2000, Sol. Phys., 61, 201

Smith, D. F., Hildner, E., and Quin, N P. M. 1992, Sol. Phys., 137, 317.

St Cyr, O. C. and Webb, D. F. 1991, Sol. Phys., 136, 379

Tandberg-Hanssen, E. 1995, The Nature of Solar Prominences, Kluwer, Dordrecht

Wang, H., \& Goode, P. 1998, in ASP Conf. Ser. Vol. 140, Synoptic Solar Physics, ed. K. S. Balasubramanian, J. W. Harvey, \& D. M. Rabin, 497

Webb, D. F. \& Hundhausen, A. J. 1987, Sol. Phys., 108, 383.

Webb, D. F., Krieger, A. S. \& Rust, D. M., 1976, Sol. Phys., 48,159. 
This is an unedited preprint of an article accepted for publication in Astrophysical Journal. The final published article may differ from this preprint.

Copyright 2002 by The American Astronomical Society. Please cite as 'ApJ preprint doi:10.1086/367614'.

$-17-$

Yang, G. \& Wang, Y. 2002, Porc. COSPAR Colloquium, in press. 
This is an unedited preprint of an article accepted for publication in Astrophysical Journal. The final published article may differ from this preprint.

Copyright 2002 by The American Astronomical Society. Please cite as 'ApJ preprint doi:10.1086/367614'.

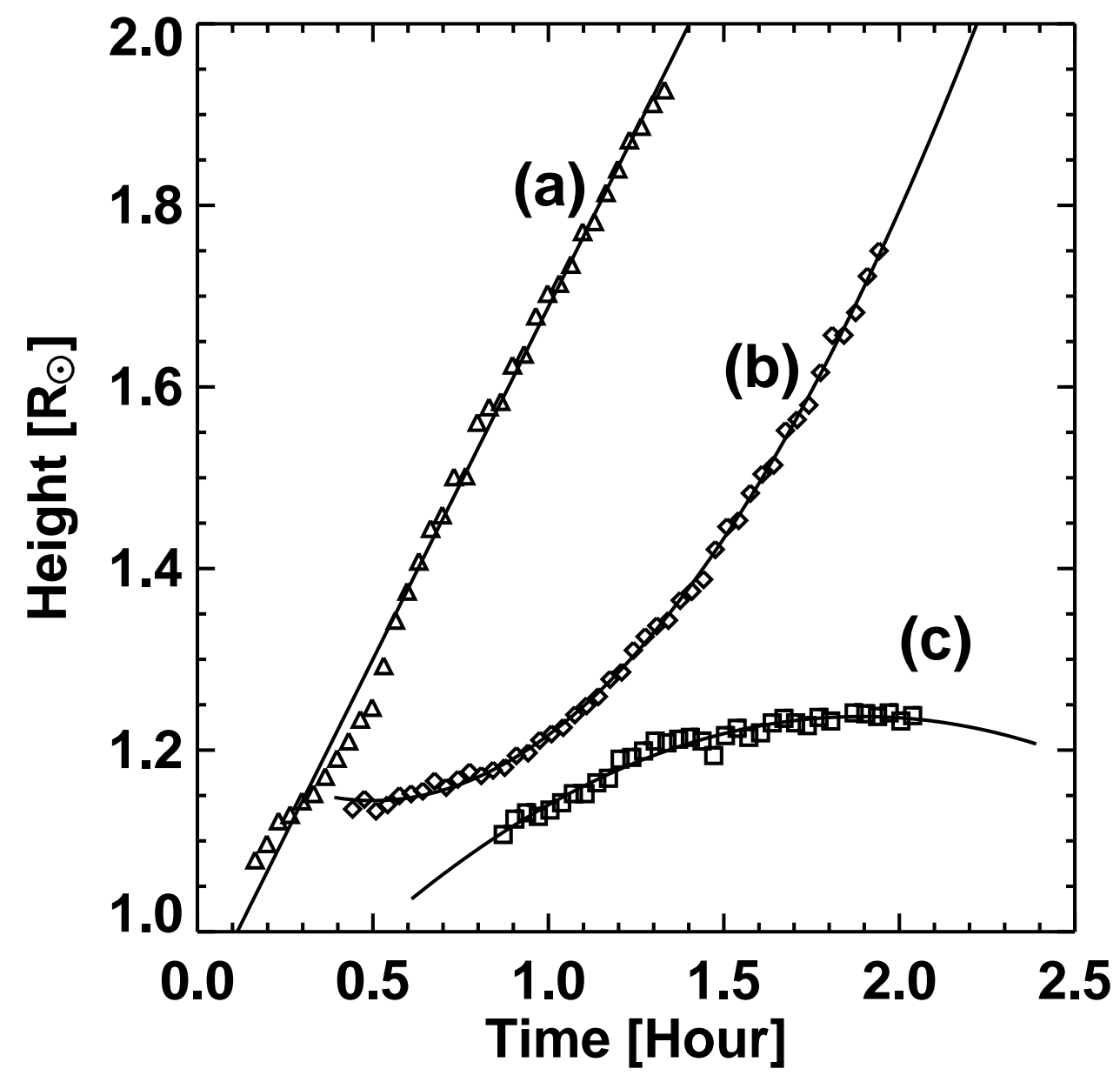

Fig. 1.- Various types of prominence trajectories found in our data. The height-time measurements fit to (a) straight line, (b) parabola implying acceleration, and (c) parabola implying deceleration. 
This is an unedited preprint of an article accepted for publication in Astrophysical Journal. The final published article may differ from this preprint.

Copyright 2002 by The American Astronomical Society. Please cite as 'ApJ preprint doi:10.1086/367614'.
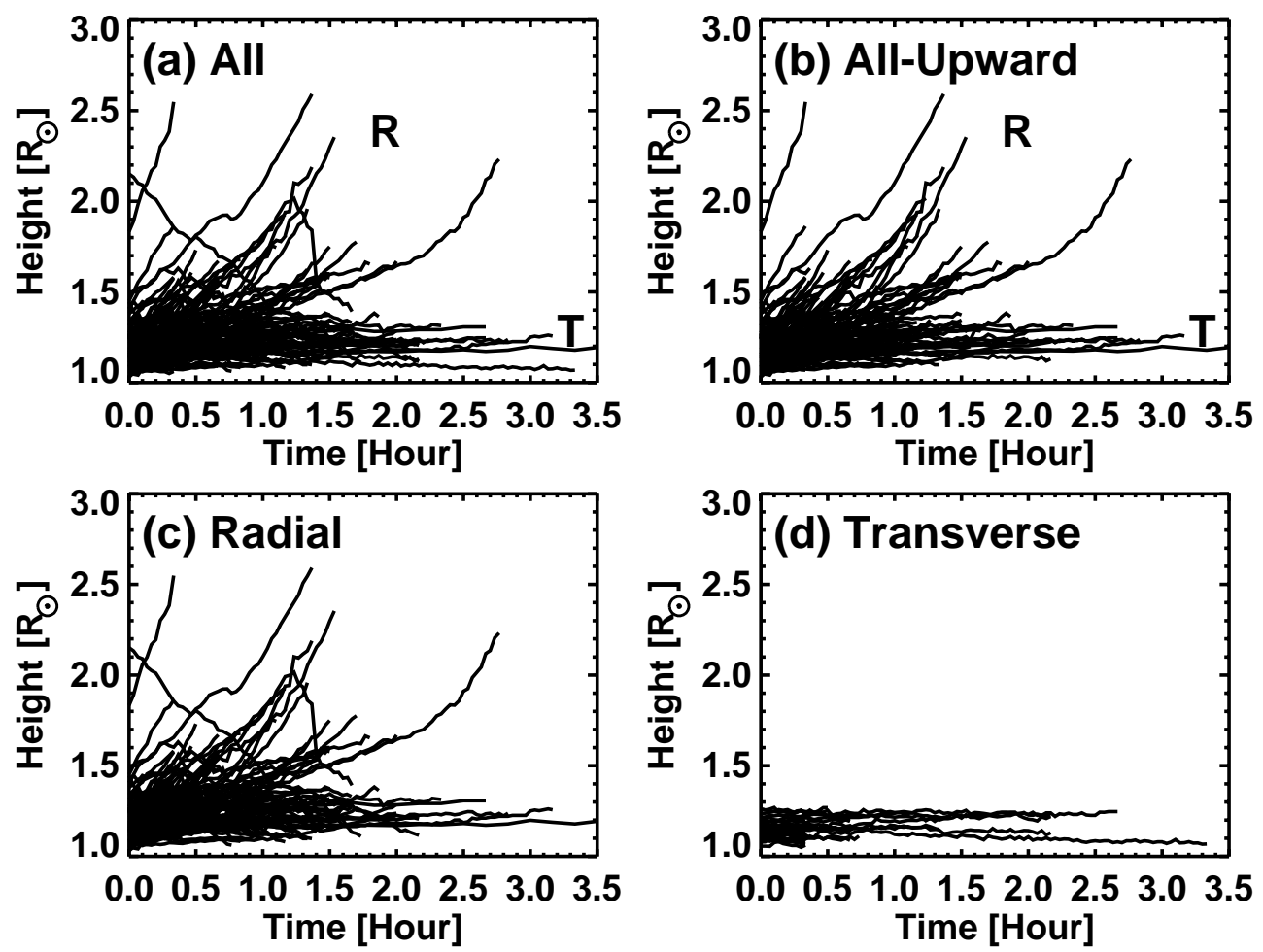

Fig. 2.- Trajectories of all the prominence eruptions for which height-time measurements were made (a) complete trajectories, and (b) the upward portion of the trajectories. $\mathrm{R}$ and $\mathrm{T}$ denote radial and transverse populations. Trajectories of the (c) R events and (d) T events plotted separately. 
This is an unedited preprint of an article accepted for publication in Astrophysical Journal. The final published article may differ from this preprint.

Copyright 2002 by The American Astronomical Society. Please cite as 'ApJ preprint doi:10.1086/367614'.
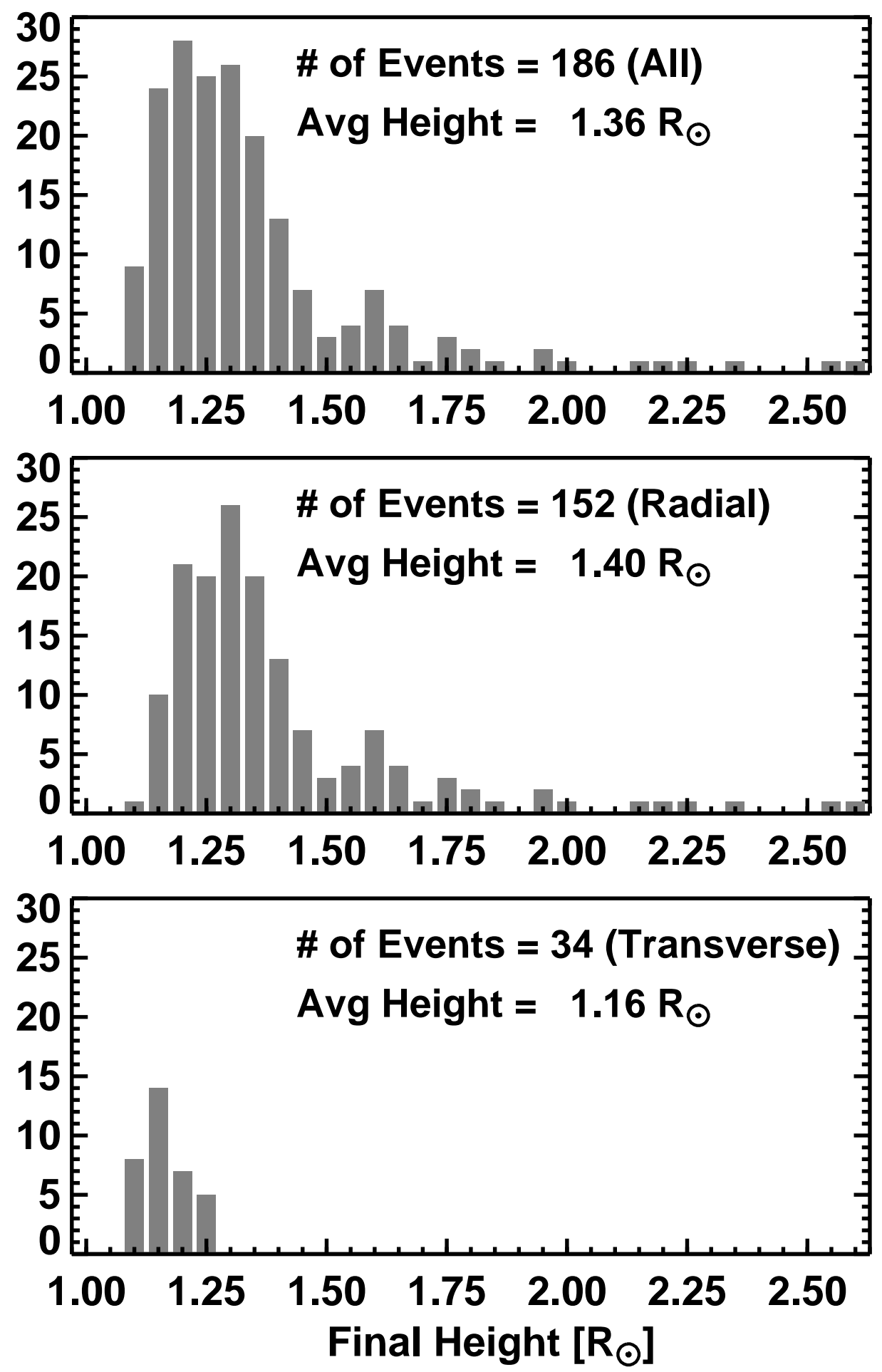

Fig. 3.- Maximum heights reached by the prominences (a) all events, (b) radial events and (c) transverse events. The heights are measured from the disk center. 
This is an unedited preprint of an article accepted for publication in Astrophysical Journal. The final published article may differ from this preprint.

Copyright 2002 by The American Astronomical Society. Please cite as 'ApJ preprint doi:10.1086/367614'.
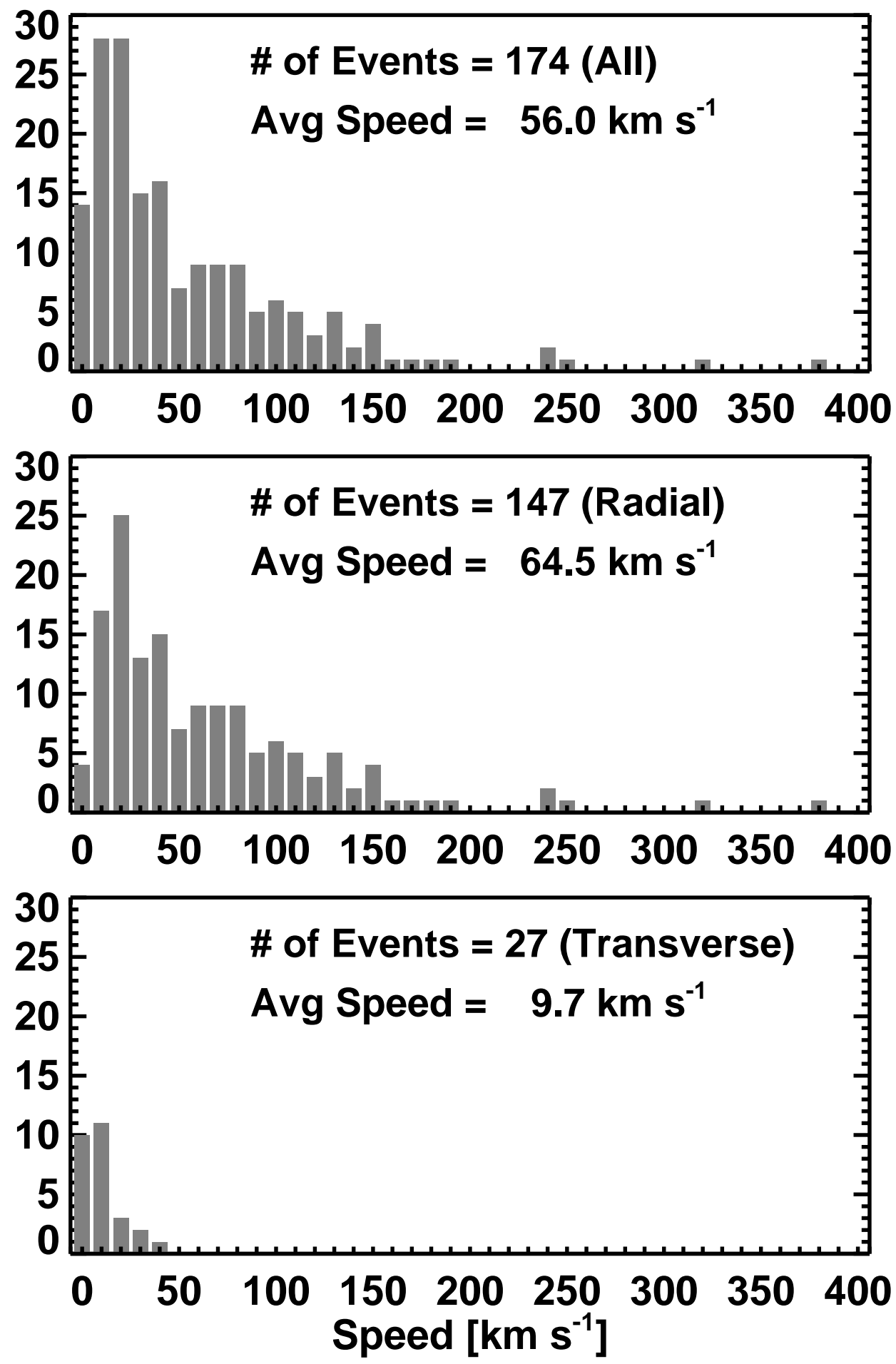

Fig. 4. - The average speed to maximum of the prominence eruption events: (a) all events, (b) radial events, and (c) transverse events. 
This is an unedited preprint of an article accepted for publication in Astrophysical Journal. The final published article may differ from this preprint.

Copyright 2002 by The American Astronomical Society. Please cite as 'ApJ preprint doi:10.1086/367614'.

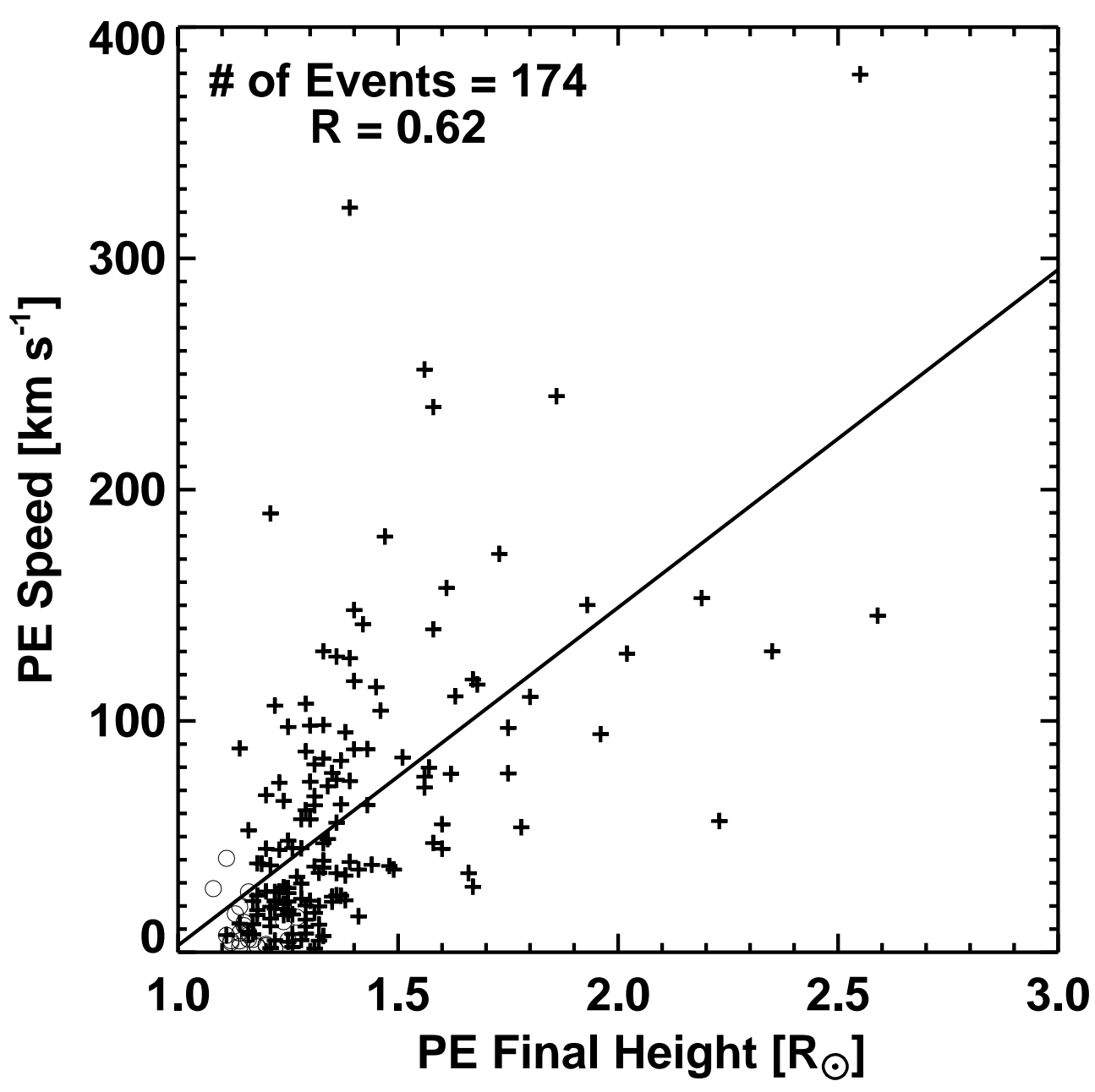

Fig. 5.- Relation between the average speed of eruptive prominences and their final height. As expected, the $\mathrm{T}$ events are in the lower left corner. The straight line is a fit to the data points. The ' + ' symbol and open circles correspond to the radial and transverse events, respectively. 
This is an unedited preprint of an article accepted for publication in Astrophysical Journal. The final published article may differ from this preprint.

Copyright 2002 by The American Astronomical Society. Please cite as 'ApJ preprint doi:10.1086/367614'.
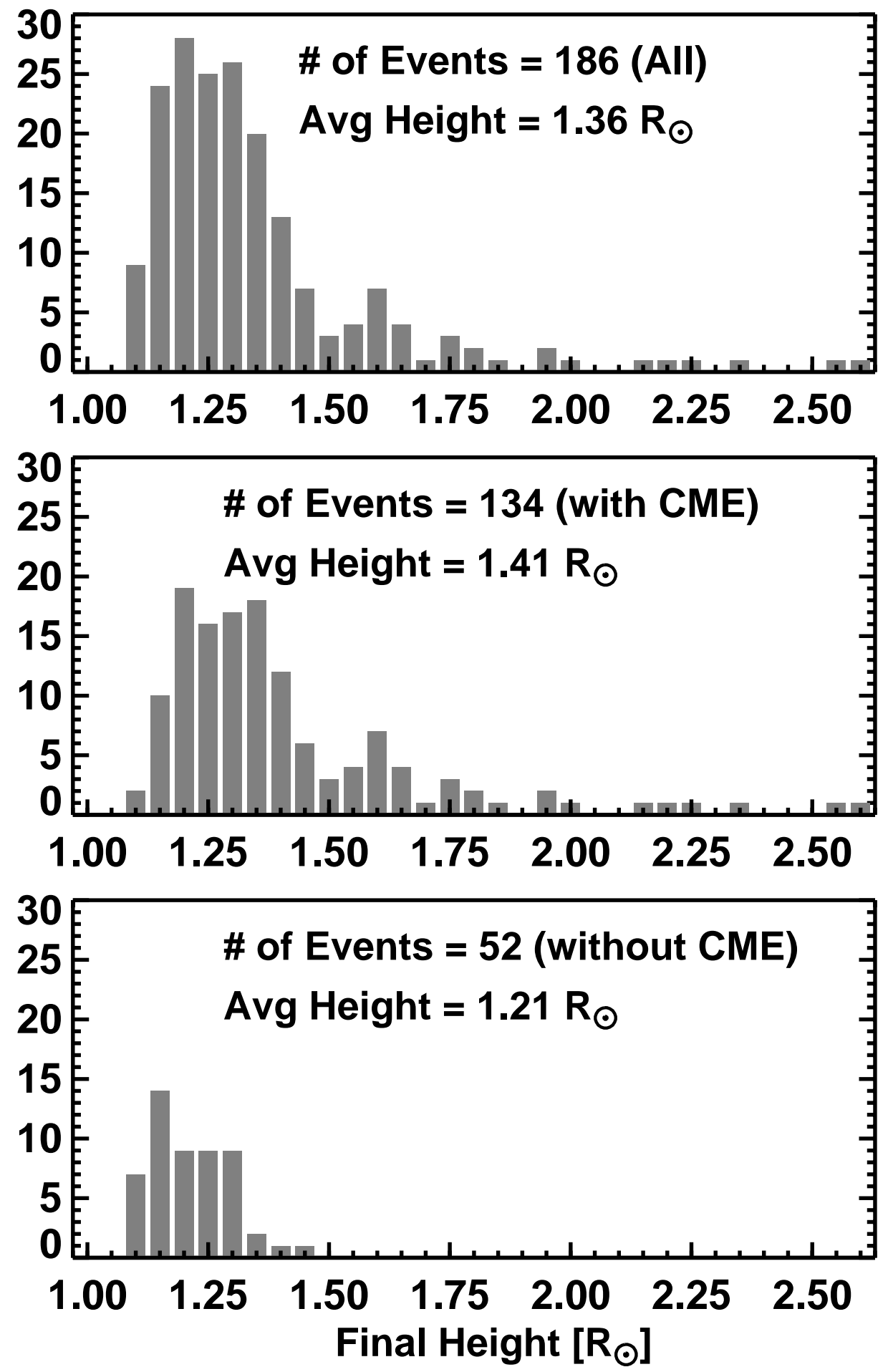

Fig. 6.- Histograms of the maximum heights reached by prominences: (a) all events, (b) events associated with CMEs, and (c) events not associated with CMEs. The distributions are remarkably similar to those in Fig. 3, if we identify the radial events with CME-associated prominence events and the transverse events with CMEless prominence events. 
This is an unedited preprint of an article accepted for publication in Astrophysical Journal. The final published article may differ from this preprint.

Copyright 2002 by The American Astronomical Society. Please cite as 'ApJ preprint doi:10.1086/367614'.

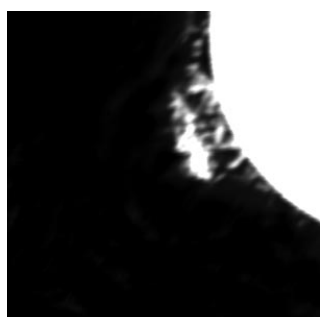

(a) $2000 / 10 / 2200: 28$

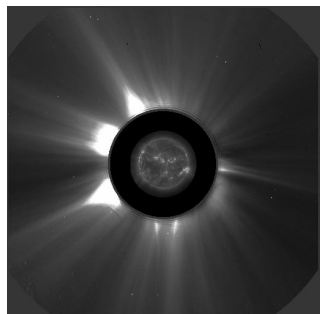

(e) $2000 / 10 / 2200: 50$

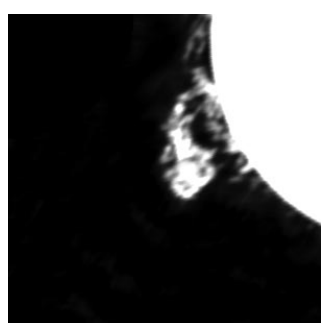

(b) 2000/10/22 00:48

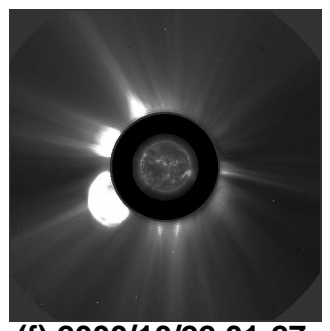

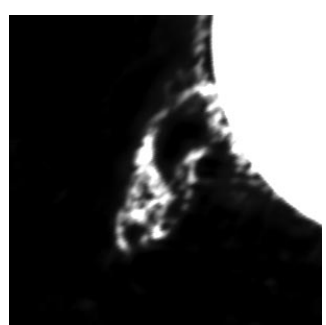

(c) 2000/10/22 01:08

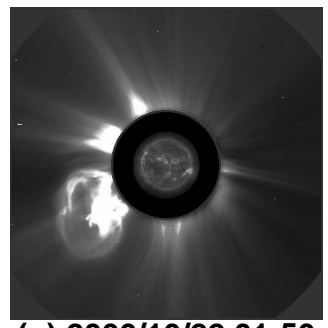

(g) 2000/10/22 01:50

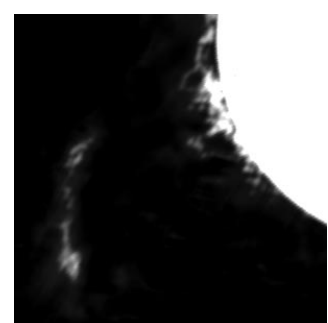

(d) 2000/10/22 01:28

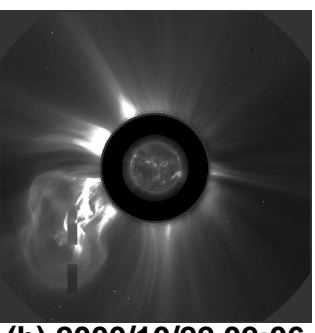

(h) 2000/10/22 02:06

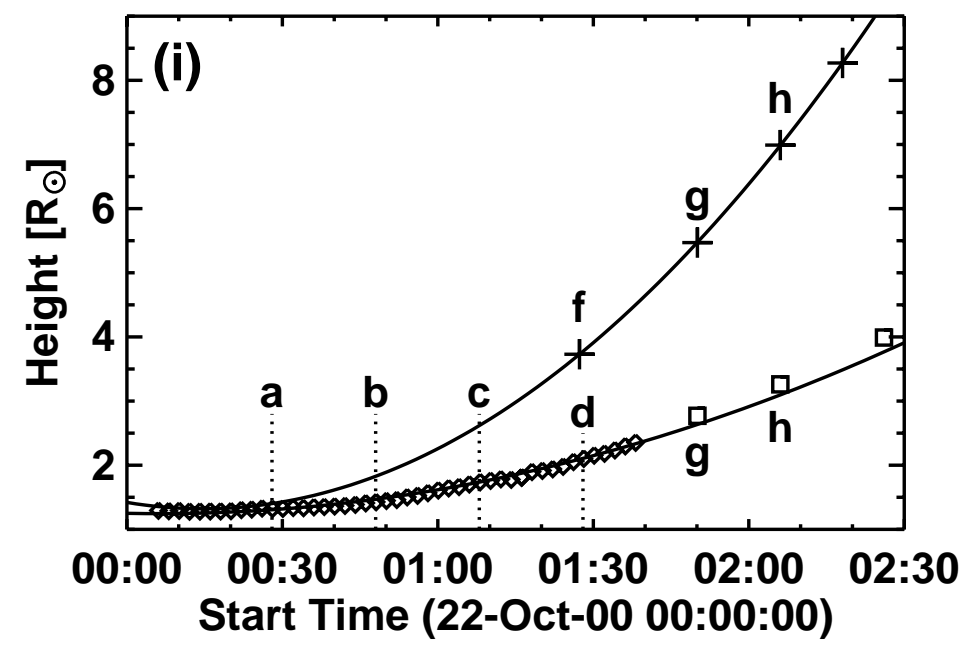

Fig. 7.- (a-d) Eruption of the 2000 October 22 microwave prominence from the east limb. (e-h) SOHO/LASCO images of the white light CME at several instances. (i) The height-time plots of the CME (upper curve) and the eruptive prominence (lower curve). The diamonds represent prominence height measured from the NoRH images. The squares denote the height of the prominence core measured from the LASCO images. The curves were obtained by fitting a second order polynomials to the data points. The times corresponding to the microwave and white light images in (a-h) are indicated on the height-time plots. 
This is an unedited preprint of an article accepted for publication in Astrophysical Journal. The final published article may differ from this preprint.

Copyright 2002 by The American Astronomical Society. Please cite as 'ApJ preprint doi:10.1086/367614'.

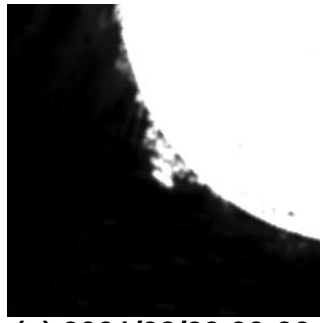

(a) $2001 / 08 / 29$ 02:00

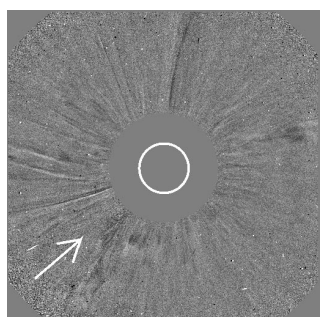

(e) $2001 / 08 / 2902: 50$
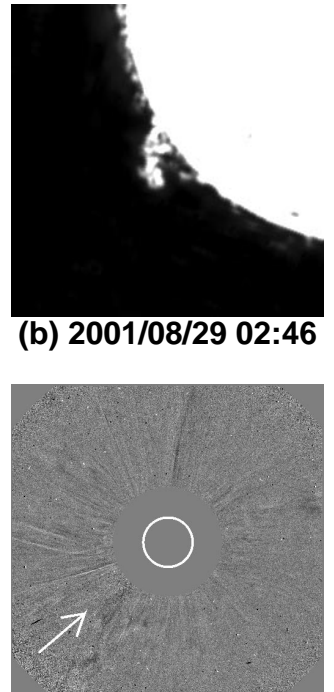

(f) 2001/08/29 03:06

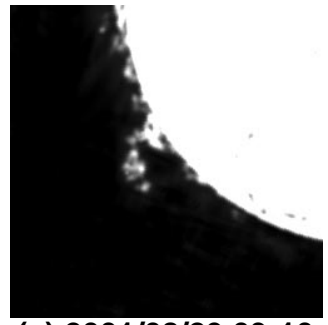

(c) $2001 / 08 / 2903: 10$

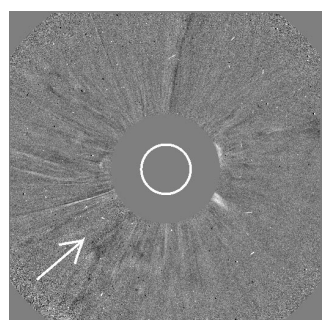

(g) $2001 / 08 / 29$ 03:26

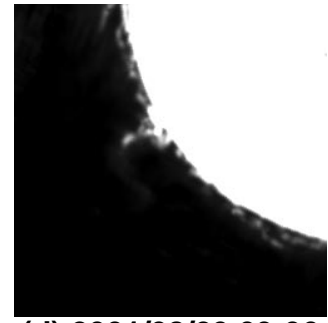

(d) $2001 / 08 / 2903: 30$

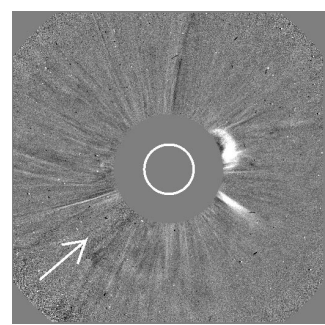

(h) 2001/08/29 03:50

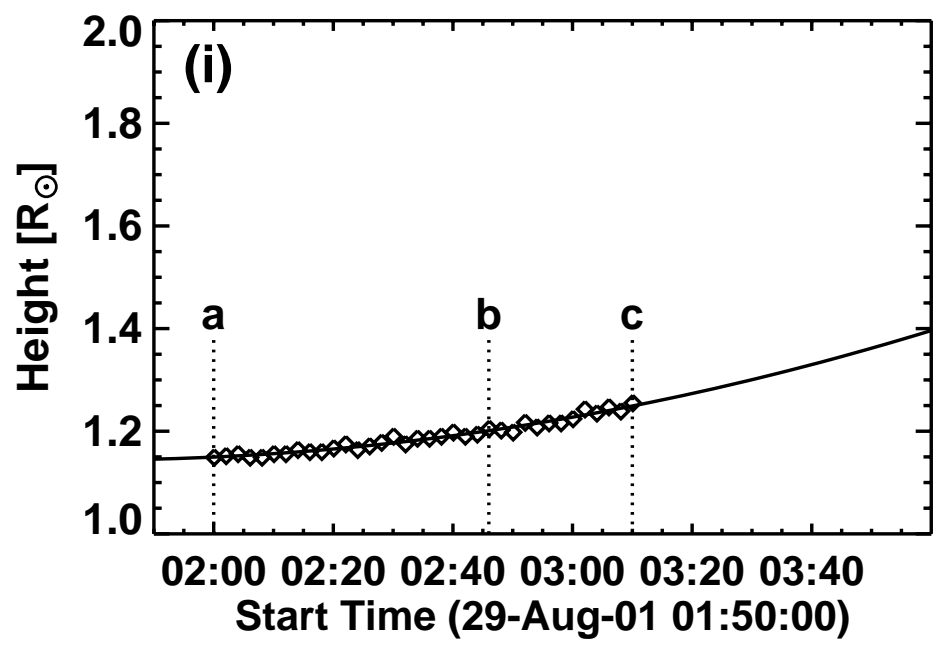

Fig. 8. - Comparison between microwave and white light images corresponding to the 2000 Aug. 29 prominence eruption event. (a-h) The prominence rises from the southeast limb and then moves northwards (parallel to the limb) before fading out. (g-h) LASCO C2 running difference images showing no changes along the position angle (marked by arrows) of the prominence. (i) The height-time plot of the prominence. Three instances corresponding to the microwaves images (a-c) are marked on the height-time plot. 
This is an unedited preprint of an article accepted for publication in Astrophysical Journal. The final published article may differ from this preprint.

Copyright 2002 by The American Astronomical Society. Please cite as 'ApJ preprint doi:10.1086/367614'.
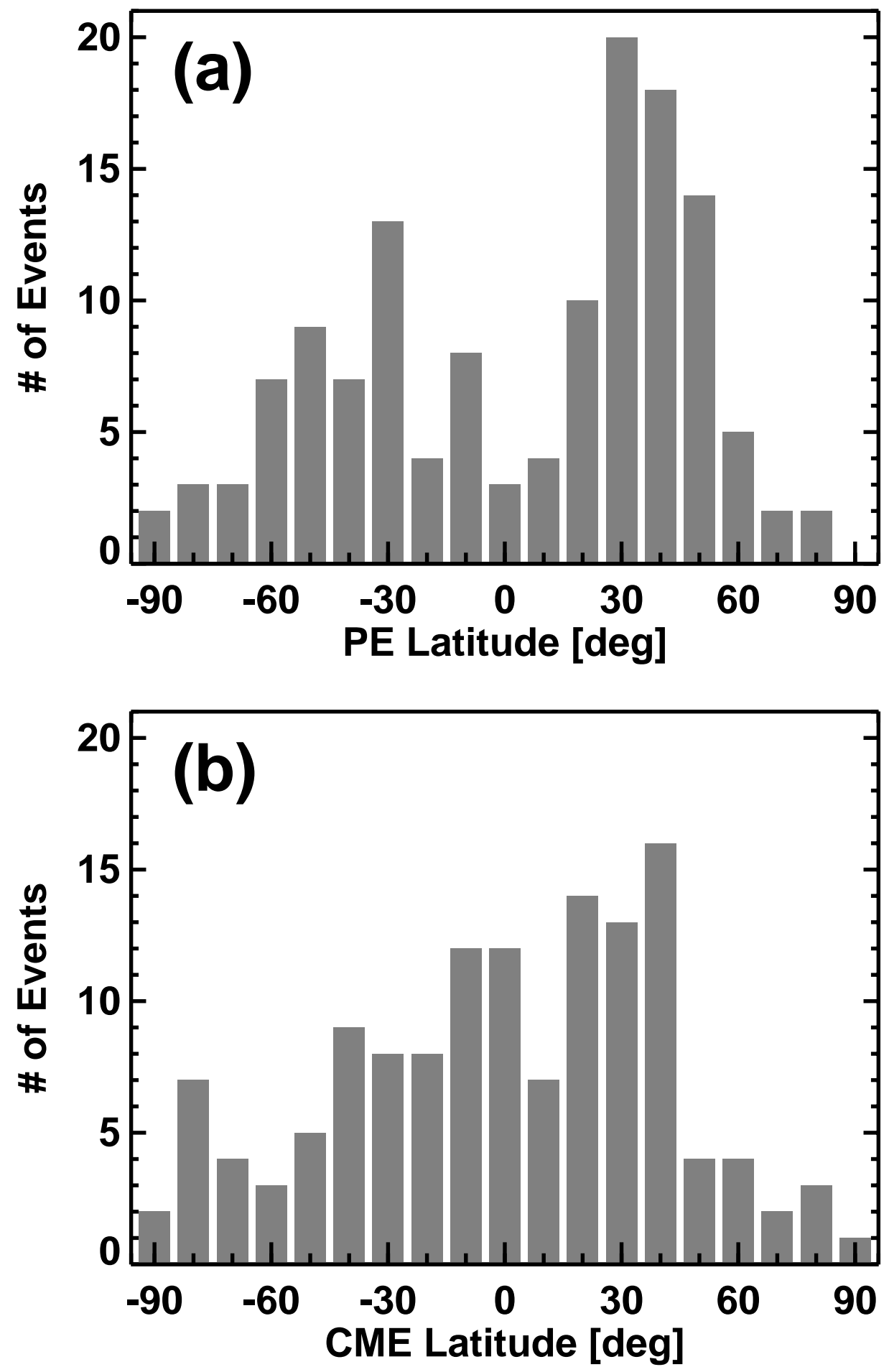

Fig. 9.- Distribution of the latitude of eruption for the prominences (top) and the corresponding CMEs (bottom). Note that the distribution is bimodal for the prominences while its a broad distribution for the CMEs peaking near the equator. 
This is an unedited preprint of an article accepted for publication in Astrophysical Journal. The final published article may differ from this preprint.

Copyright 2002 by The American Astronomical Society. Please cite as 'ApJ preprint doi:10.1086/367614'.
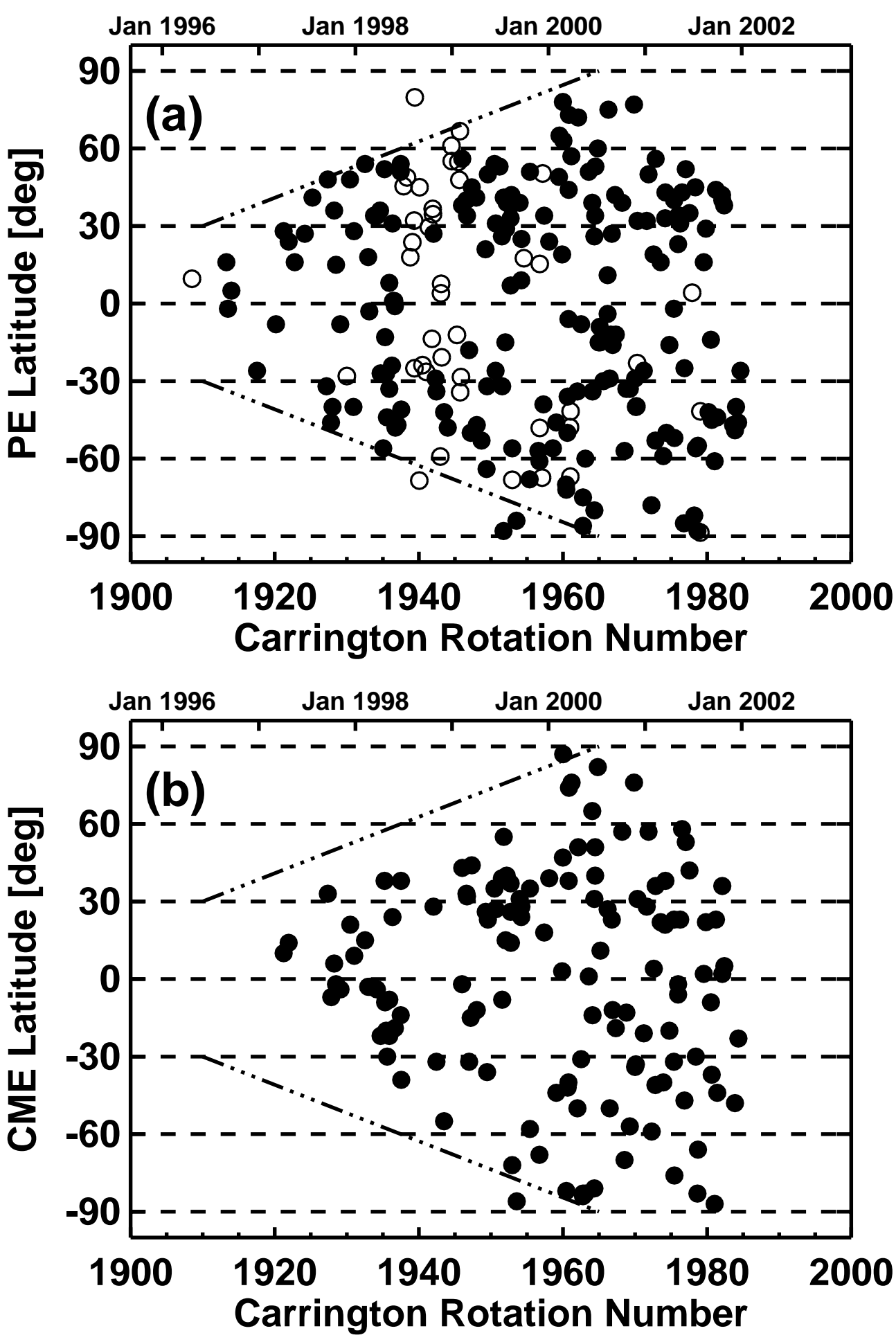

Fig. 10.- (a) Another view of the plot in Fig. 9, but showing the solar-cycle variation of the latitude of eruption. The filled circles correspond to the prominence eruptions studied in this paper. The open circles represent eruptions that occurred during SOHO data gaps. (b) The latitudes of the CMEs corresponding to the prominence eruptions as a function of Carrington rotation numbers. 
This is an unedited preprint of an article accepted for publication in Astrophysical Journal. The final published article may differ from this preprint.

Copyright 2002 by The American Astronomical Society. Please cite as 'ApJ preprint doi:10.1086/367614'.
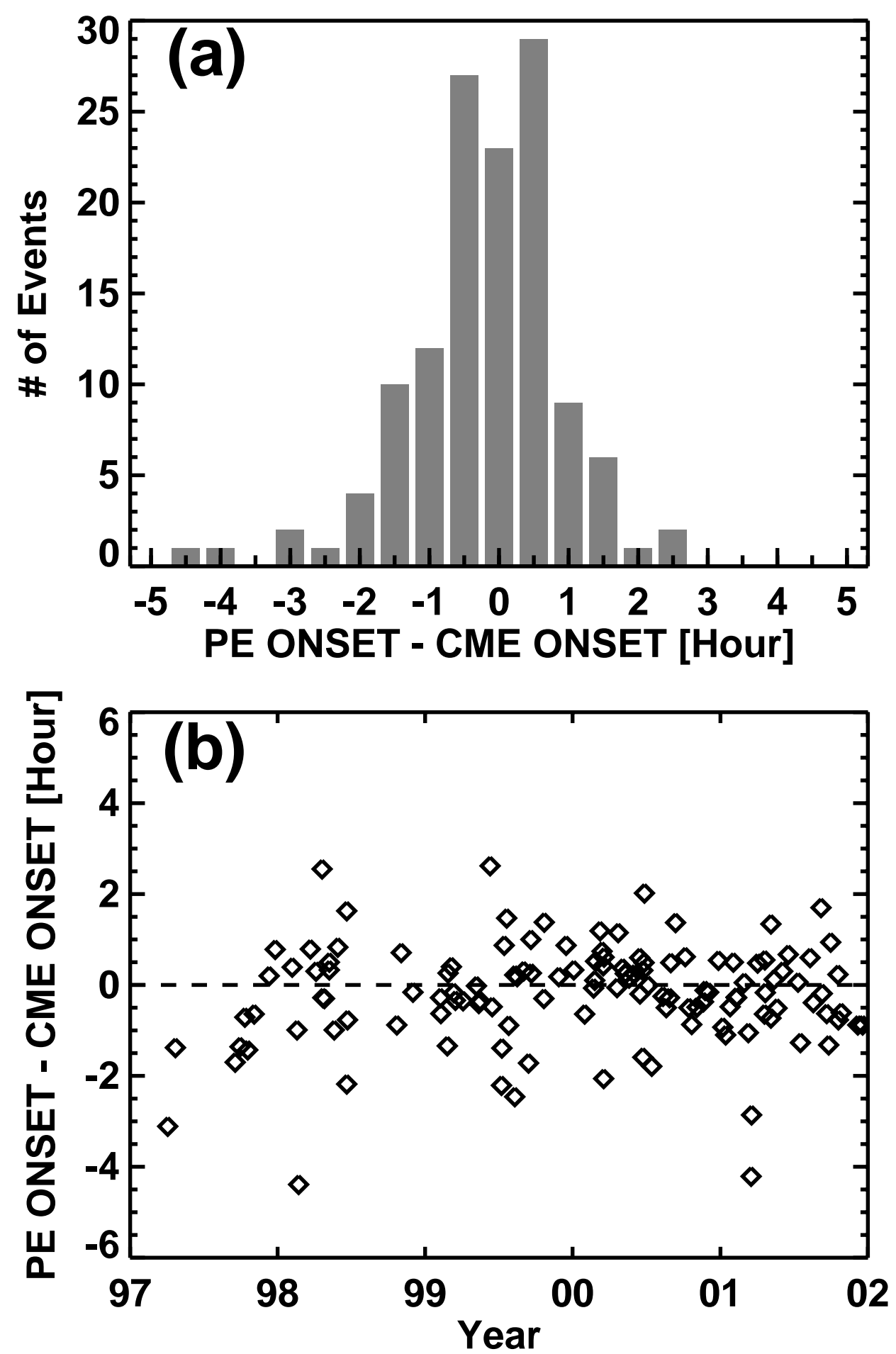

Fig. 11.- (a) Comparison between the onset times of the prominence and CME events. Negative numbers mean CME onsets preceding prominence event onsets. (b) Solar cycle variation of the onset time differences. 
This is an unedited preprint of an article accepted for publication in Astrophysical Journal. The final published article may differ from this preprint.

Copyright 2002 by The American Astronomical Society. Please cite as 'ApJ preprint doi:10.1086/367614'.
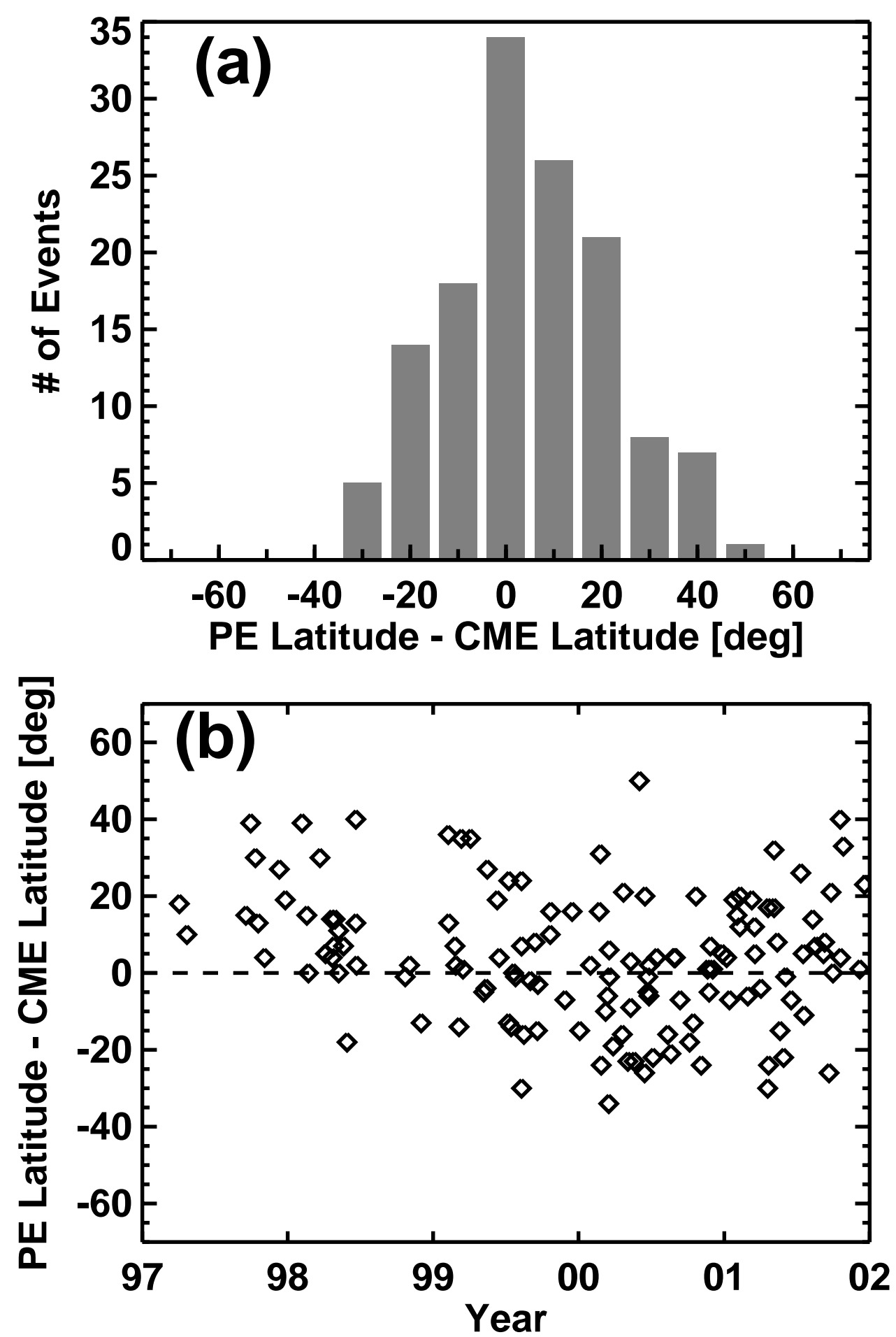

Fig. 12.- (a) Positional relationship between CMEs and prominence events as a difference in central position angles. (b) solar cycle variation of the the position angle offset. 
This is an unedited preprint of an article accepted for publication in Astrophysical Journal. The final published article may differ from this preprint.

Copyright 2002 by The American Astronomical Society. Please cite as 'ApJ preprint doi:10.1086/367614'.

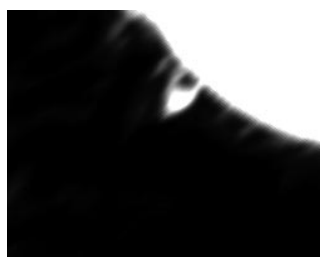

(a) 2001/12/19 23:51

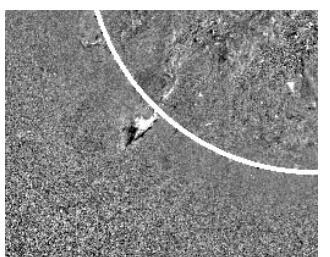

(e) 2001/12/19 23:48

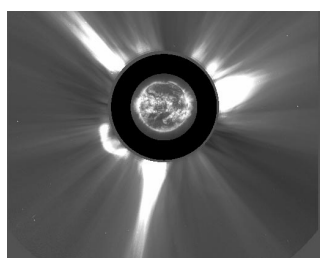

(i) $2001 / 12 / 2000: 54$

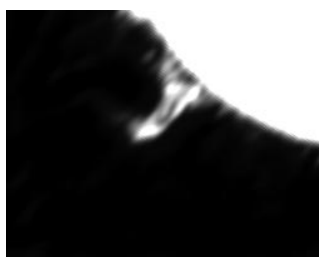

(b) 2001/12/20 00:11

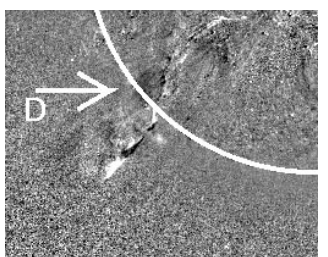

(f) $2001 / 12 / 2000: 12$

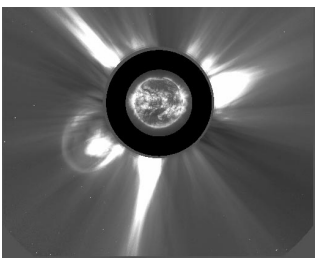

(j) 2001/12/20 01:31

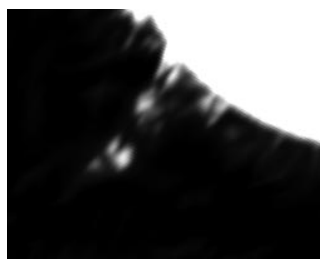

(c) 2001/12/20 00:31

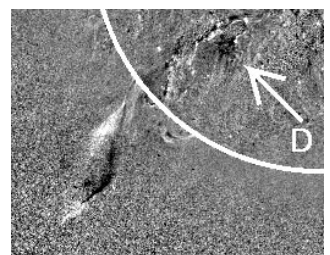

(g) 2001/12/20 00:36

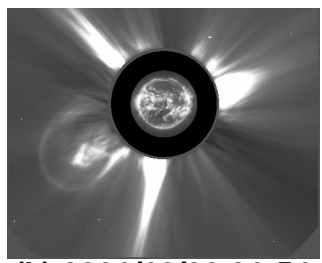

(k) 2001/12/20 01:54

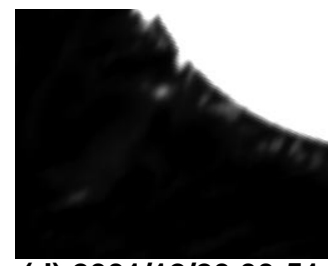

(d) $2001 / 12 / 2000: 51$

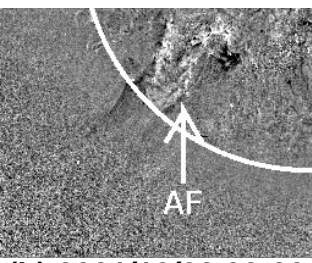

(h) $2001 / 12 / 2002: 00$

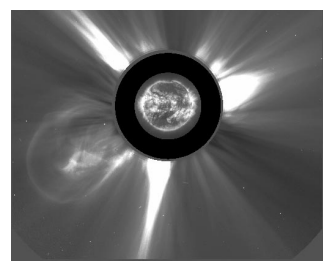

(I) $2001 / 12 / 2002: 06$

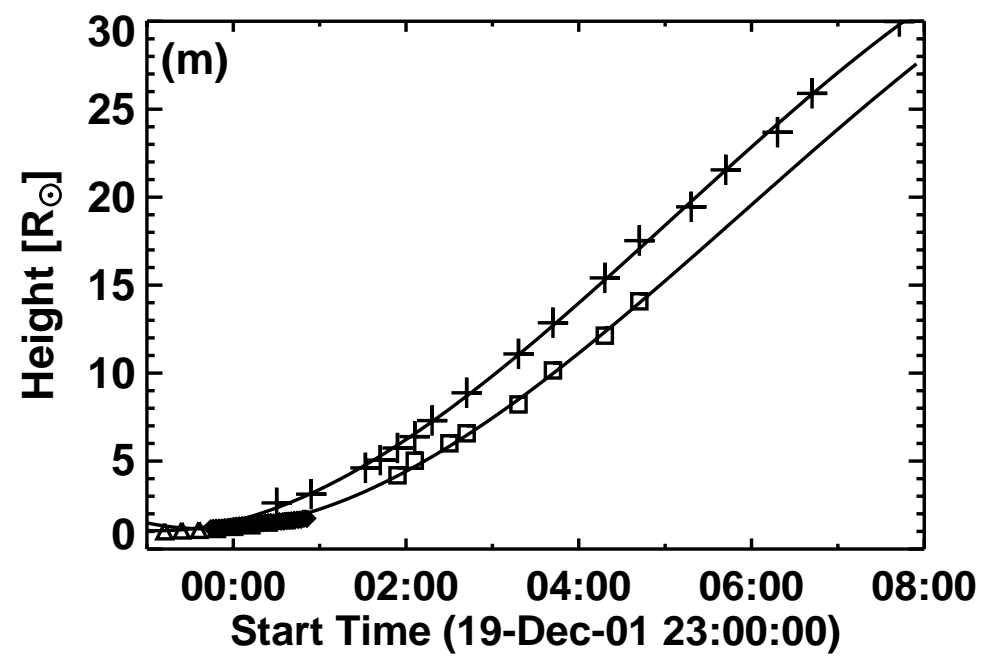

Fig. 13. - Multiwavelength observations of the 2001 December 19-20 prominence eruption: (a-d) microwave images. (e-h) running difference images from SOHO/EIT at $195 \stackrel{\circ}{A}$ showing the prominence eruption as well as the associated activity on the disk. (i-l) white light images showing the CME with its three part structure. (m) Height-time plots of the CME and the prominence core (microwave and white light combined). 
This is an unedited preprint of an article accepted for publication in Astrophysical Journal. The final published article may differ from this preprint.

Copyright 2002 by The American Astronomical Society. Please cite as 'ApJ preprint doi:10.1086/367614'.
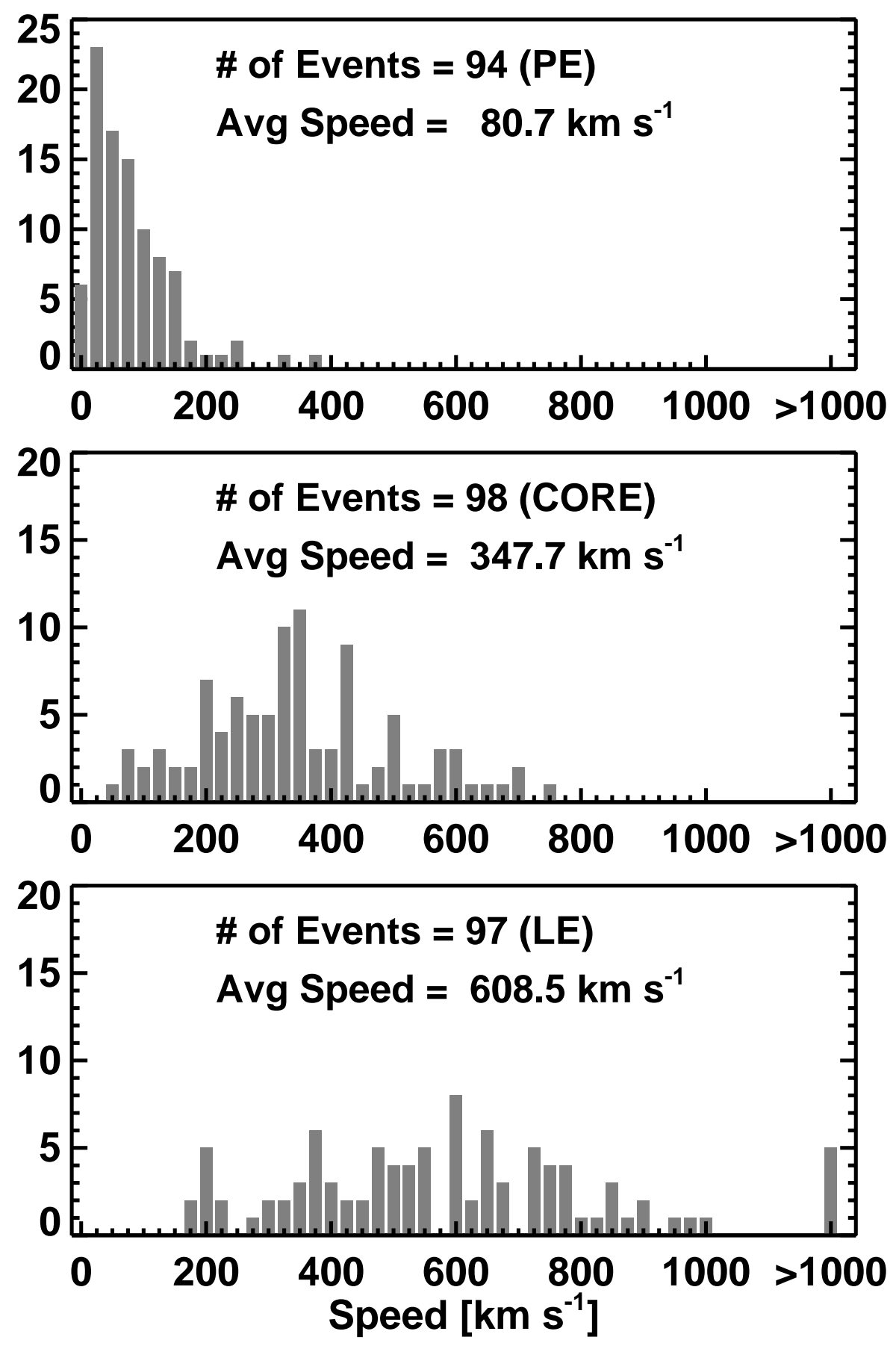

Fig. 14. - Distribution of the CME core speeds (middle panel) compared to that for associated prominence speeds (top panel) and CME speeds (bottom panel). Note that the prominence speeds were measured much closer to the solar surface. The CME cores are expected to be the evolved forms of the prominences. The speeds of 4 prominences could not be measured because they occurred close to the boundary of the observation window. There was only a single point for one of the CME leading edges, so we could not measure the speed. 
This is an unedited preprint of an article accepted for publication in Astrophysical Journal. The final published article may differ from this preprint.

Copyright 2002 by The American Astronomical Society. Please cite as 'ApJ preprint doi:10.1086/367614'.

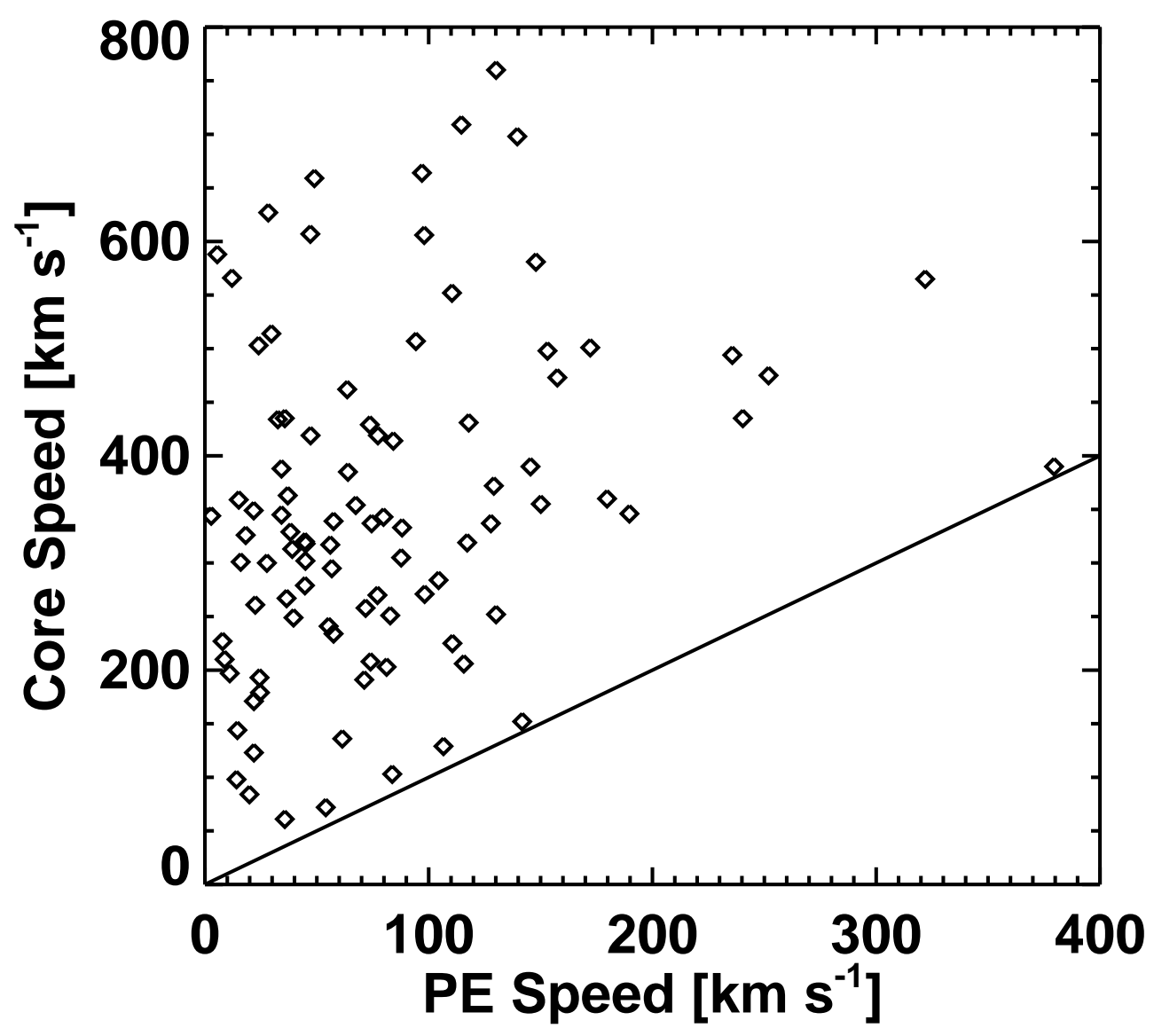

Fig. 15. - Scatter plot of the prominence and CME core speeds. The straight line represents the equal speeds. Note that none of the core speeds are below the straight line. This is expected because the CME cores are the evolved forms of the prominences and are expected to have higher speeds because of the continued acceleration. 
This is an unedited preprint of an article accepted for publication in Astrophysical Journal. The final published article may differ from this preprint.

Copyright 2002 by The American Astronomical Society. Please cite as 'ApJ preprint doi:10.1086/367614'.

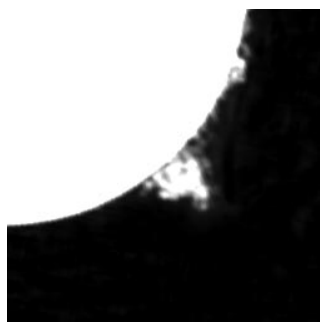

(a) 1998/06/01 06:06

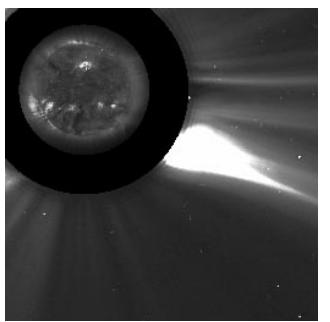

(e) 1998/06/01 06:06

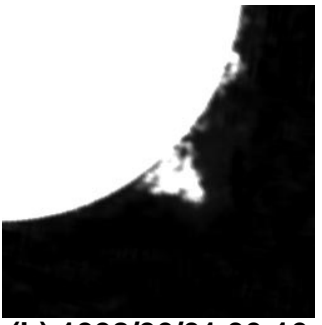

(b) $1998 / 06 / 0106: 16$

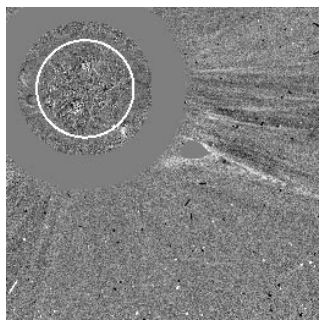

(f) $1998 / 06 / 0106: 31$

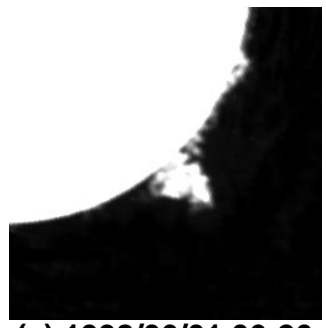

(c) 1998/06/01 06:26

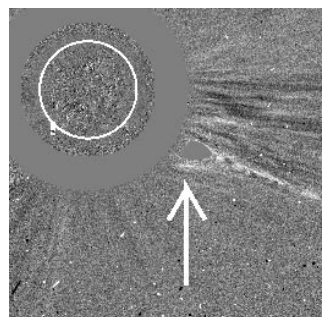

(g) 1998/06/01 07:02

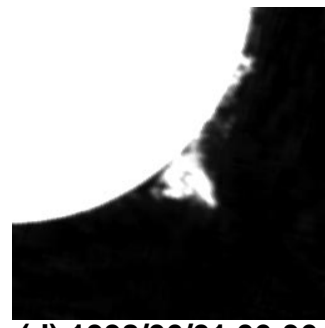

(d) $1998 / 06 / 0106: 36$

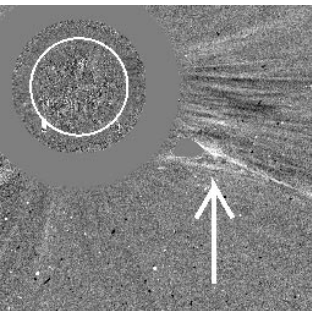

(h) $1998 / 06 / 0107: 34$

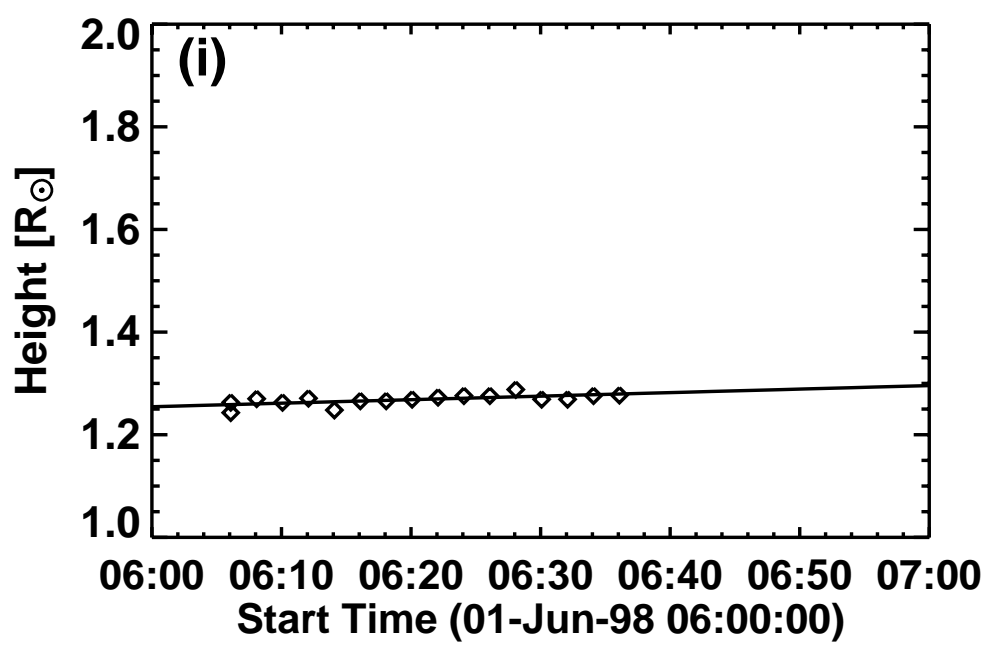

Fig. 16.- (a-d) The 1998 June 01 prominence eruption, and (e-h) the associated streamer change observed by $\mathrm{SOHO} / \mathrm{LASCO}$. (i) The height-time plot of the prominence, showing a slight increase in height and then becoming stationary again. The first LASCO image is a direct image with a superposed EIT image. The subsequent ones are running difference images showing that that the streamer had slightly distended (pointed by arrows). 
This is an unedited preprint of an article accepted for publication in Astrophysical Journal. The final published article may differ from this preprint.

Copyright 2002 by The American Astronomical Society. Please cite as 'ApJ preprint doi:10.1086/367614'.

Table 1. Prominence Events and the Associated CMEs

\begin{tabular}{|c|c|c|c|c|c|c|c|c|c|c|c|}
\hline & \multicolumn{6}{|c|}{$\mathrm{PE}$} & \multicolumn{5}{|c|}{$\mathrm{CME}$} \\
\hline & Date & $\begin{array}{l}\text { Time } \\
\text { (UT) }\end{array}$ & $\begin{array}{c}\text { PA } \\
(\text { deg })\end{array}$ & $\begin{array}{c}\text { Speed } \\
\left(\mathrm{km} \mathrm{s}^{-1}\right)\end{array}$ & $\begin{array}{c}\text { Height } \\
\left(\mathrm{R}_{\odot}\right)\end{array}$ & Type & $\begin{array}{l}\text { Time } \\
(\mathrm{UT})\end{array}$ & $\begin{array}{c}\text { PA } \\
(\text { deg })\end{array}$ & $\begin{array}{c}\text { Width } \\
\text { (deg) }\end{array}$ & $\begin{array}{c}\text { Speed } \\
\left(\mathrm{km} \mathrm{s}^{-1}\right)\end{array}$ & Core \\
\hline 001 & 1996 Aug 30 & $22: 49$ & 74 & 7.5 & 1.16 & $\mathrm{~T}$ & $\mathrm{~S}$ & $\ldots$ & $\ldots$ & $\cdots$ & $\ldots$ \\
\hline 002 & 1996 Sep 5 & 03:00 & 268 & -12.7 & 1.12 & $\mathrm{~T}$ & $\mathrm{~S}$ & $\cdots$ & $\cdots$ & $\cdots$ & $\cdots$ \\
\hline 003 & 1996 Sep 18 & 01:05 & 85 & 34.3 & 1.32 & $\mathrm{R}$ & $\mathrm{S}$ & $\ldots$ & $\ldots$ & $\ldots$ & $\ldots$ \\
\hline 004 & 1996 Dec 24 & $01: 26$ & 244 & 20.2 & 1.29 & $\mathrm{R}$ & $\mathrm{N}$ & $\ldots$ & $\ldots$ & $\ldots$ & $\ldots$ \\
\hline 005 & 1997 Mar 6 & $00: 55$ & 98 & 40.6 & 1.11 & $\mathrm{~T}$ & $\mathrm{~N}$ & $\ldots$ & $\ldots$ & $\ldots$ & $\ldots$ \\
\hline 006 & 1997 Apr 4 & $03: 21$ & 298 & 14.1 & 1.29 & $\mathrm{R}$ & 05:09 & 280 & 72 & 185 & $\mathrm{Y}$ \\
\hline 007 & 1997 Apr 23 & 03:01 & 66 & 44.7 & 1.60 & $\mathrm{R}$ & $05: 30$ & 76 & 45 & 634 & $\mathrm{Y}$ \\
\hline 008 & 1997 May 16 & 03:01 & 286 & 4.5 & 1.25 & $\mathrm{R}$ & $\mathrm{N}$ & $\ldots$ & $\ldots$ & $\ldots$ & $\ldots$ \\
\hline 009 & 1997 Jun 23 & $22: 31$ & 297 & -1.2 & 1.26 & $\mathrm{~T}$ & $\mathrm{~N}$ & $\ldots$ & $\ldots$ & $\ldots$ & $\ldots$ \\
\hline 010 & 1997 Jul 22 & 06:01 & 49 & 19.7 & 1.14 & $\mathrm{~T}$ & $\mathrm{~N}$ & $\ldots$ & $\ldots$ & $\ldots$ & $\ldots$ \\
\hline 011 & 1997 Sep 13 & $23: 51$ & 122 & 22.2 & 1.30 & $\mathrm{R}$ & $\mathrm{N}$ & $\ldots$ & $\ldots$ & $\cdots$ & $\cdots$ \\
\hline 012 & 1997 Sep 18 & 04:01 & 318 & 2.8 & 1.20 & $\mathrm{~T}$ & $06: 35$ & 303 & 20 & 374 & $\mathrm{Y}$ \\
\hline 013 & 1997 Sep 30 & $22: 51$ & 224 & 98.2 & 1.33 & $\mathrm{R}$ & $01: 29^{\mathrm{a}}$ & 263 & 67 & 502 & $\mathrm{Y}$ \\
\hline 014 & 1997 Oct 6 & $04: 11$ & 230 & 16.6 & 1.13 & $\mathrm{~T}$ & $\mathrm{~N}$ & $\ldots$ & $\ldots$ & $\ldots$ & $\ldots$ \\
\hline 015 & 1997 Oct 12 & $04: 21$ & 306 & 47.1 & 1.33 & $\mathrm{R}$ & $05: 35$ & 276 & 105 & 752 & $\mathrm{Y}$ \\
\hline 016 & 1997 Oct 19 & 02:11 & 75 & 21.9 & 1.25 & $\mathrm{R}$ & $04: 42$ & 92 & 63 & 373 & $\mathrm{Y}$ \\
\hline 017 & 1997 Nov 4 & $22: 31$ & 262 & 11.1 & 1.29 & $\mathrm{R}$ & $00: 18^{\mathrm{a}}$ & 266 & 75 & 275 & Y \\
\hline 018 & 1997 Dec 11 & $23: 51$ & 318 & 61.4 & 1.29 & $\mathrm{R}$ & $01: 27^{\mathrm{a}}$ & 291 & 80 & 211 & $\mathrm{Y}$ \\
\hline 019 & 1997 Dec 24 & $04: 26$ & 130 & 20.8 & 1.24 & $\mathrm{R}$ & $\mathrm{S}$ & $\ldots$ & $\ldots$ & $\ldots$ & $\ldots$ \\
\hline 020 & 1997 Dec 26 & $23: 46$ & 298 & 19.9 & 1.32 & $\mathrm{R}$ & $00: 33^{\mathrm{a}}$ & 279 & 63 & 231 & $\mathrm{Y}$ \\
\hline 021 & 1998 Feb 6 & $02: 21$ & 324 & 26.3 & 1.23 & $\mathrm{R}$ & $02: 55$ & 285 & 57 & 445 & $\mathrm{~N}$ \\
\hline 022 & 1998 Feb 18 & $01: 21$ & 72 & 26.0 & 1.22 & $\mathrm{R}$ & $02: 27$ & 93 & 33 & 351 & $\mathrm{~N}$ \\
\hline 023 & 1998 Feb 22 & $23: 41$ & 267 & 7.9 & 1.26 & $\mathrm{R}$ & $02: 55^{\mathrm{a}}$ & 267 & 83 & 334 & $\mathrm{Y}$ \\
\hline 024 & 1998 Mar 12 & 03:01 & 56 & 5.0 & 1.32 & $\mathrm{R}$ & $\mathrm{N}$ & $\ldots$ & $\ldots$ & $\ldots$ & $\ldots$ \\
\hline 025 & 1998 Mar 23 & $00: 21$ & 56 & 27.7 & 1.25 & $\mathrm{R}$ & $00: 50$ & 94 & 84 & 357 & $\mathrm{Y}$ \\
\hline 026 & 1998 Apr 4 & 04:11 & 54 & 13.2 & 1.24 & $\mathrm{~T}$ & $\mathrm{~N}$ & $\ldots$ & $\ldots$ & $\ldots$ & $\ldots$ \\
\hline 027 & 1998 Apr 6 & $04: 51$ & 243 & 321.9 & 1.39 & $\mathrm{R}$ & 05:04 & 248 & 62 & 878 & $\mathrm{Y}$ \\
\hline 028 & 1998 Apr 16 & $04: 46$ & 146 & 5.6 & 1.16 & $\mathrm{~T}$ & $\mathrm{~N}$ & $\ldots$ & $\ldots$ & $\ldots$ & $\ldots$ \\
\hline 029 & 1998 Apr 21 & $03: 26$ & 322 & 26.3 & 1.20 & $\mathrm{R}$ & $02: 13$ & 308 & 17 & 583 & $\mathrm{~N}$ \\
\hline 030 & 1998 Apr 23 & 05:06 & 103 & 12.1 & 1.17 & $\mathrm{R}$ & $05: 27$ & 99 & 360 & 1618 & $\mathrm{Y}$ \\
\hline 031 & 1998 Apr 27 & 02:06 & 117 & 48.2 & 1.25 & $\mathrm{R}$ & 03:01 & 110 & 40 & 760 & $\mathrm{~N}$ \\
\hline 032 & 1998 Apr 30 & $23: 46$ & 134 & -8.0 & 1.17 & $\mathrm{R}$ & $00: 58^{\mathrm{a}}$ & 120 & 44 & 859 & $\mathrm{Y}$ \\
\hline 033 & 1998 May 9 & $02: 16$ & 237 & 52.7 & 1.16 & $\mathrm{R}$ & $01: 37$ & 248 & 53 & 998 & $\mathrm{~N}$ \\
\hline 034 & 1998 May 9 & $03: 46$ & 278 & 98.0 & 1.30 & $\mathrm{R}$ & $03: 35$ & 262 & 178 & 2331 & $\mathrm{Y}$ \\
\hline 035 & 1998 May 19 & $00: 56$ & 114 & 107.4 & 1.29 & $\mathrm{R}$ & $\mathrm{N}$ & $\ldots$ & $\ldots$ & $\ldots$ & $\ldots$ \\
\hline 036 & 1998 May 21 & $03: 41$ & 301 & 77.3 & 1.75 & $\mathrm{R}$ & $05: 27$ & 294 & 51 & 822 & $\mathrm{Y}$ \\
\hline 037 & 1998 May 23 & $01: 26$ & 89 & 26.1 & 1.16 & $\mathrm{~T}$ & $\mathrm{~N}$ & $\ldots$ & $\ldots$ & $\ldots$ & $\ldots$ \\
\hline 038 & 1998 May 28 & $00: 46$ & 271 & 27.5 & 1.08 & $\mathrm{~T}$ & $\mathrm{~N}$ & $\ldots$ & $\ldots$ & $\ldots$ & $\ldots$ \\
\hline 039 & 1998 May 30 & $23: 06$ & 269 & 104.4 & 1.46 & $\mathrm{R}$ & $23: 28$ & 251 & 63 & 594 & $\mathrm{Y}$ \\
\hline 040 & 1998 Jun 1 & 06:06 & 222 & 8.0 & 1.29 & $\mathrm{R}$ & $\mathrm{S}$ & $\ldots$ & $\ldots$ & $\ldots$ & $\ldots$ \\
\hline 041 & 1998 Jun 9 & $06: 16$ & 137 & 4.2 & 1.12 & $\mathrm{~T}$ & $\mathrm{~N}$ & $\ldots$ & $\ldots$ & $\ldots$ & $\ldots$ \\
\hline 042 & 1998 Jun 21 & $06: 06$ & 324 & 2.3 & 1.18 & $\mathrm{~T}$ & $05: 35$ & 256 & 163 & 192 & $\mathrm{~N}$ \\
\hline 043 & 1998 Jun 21 & $23: 56$ & 321 & 28.3 & 1.67 & $\mathrm{R}$ & $00: 56^{\mathrm{a}}$ & 308 & 45 & 551 & $\mathrm{Y}$ \\
\hline 044 & 1998 Jun 23 & $02: 36$ & 229 & 71.2 & 1.56 & $\mathrm{R}$ & 03:59 & 231 & 92 & 434 & $\mathrm{Y}$ \\
\hline 045 & 1998 Oct 23 & $03: 26$ & 297 & 45.0 & 1.26 & $\mathrm{R}$ & $04: 54$ & 298 & 69 & 640 & $\mathrm{Y}$ \\
\hline 046 & 1998 Oct 31 & 01:06 & 119 & 8.3 & 1.14 & $\mathrm{~T}$ & $\mathrm{~N}$ & $\ldots$ & $\ldots$ & $\ldots$ & $\ldots$ \\
\hline
\end{tabular}


This is an unedited preprint of an article accepted for publication in Astrophysical Journal. The final published article may differ from this preprint.

Copyright 2002 by The American Astronomical Society. Please cite as 'ApJ preprint doi:10.1086/367614'.

Table 1 -Continued

\begin{tabular}{|c|c|c|c|c|c|c|c|c|c|c|c|}
\hline & \multicolumn{6}{|c|}{$\mathrm{PE}$} & \multicolumn{5}{|c|}{$\mathrm{CME}$} \\
\hline & Date & $\begin{array}{l}\text { Time } \\
(\mathrm{UT})\end{array}$ & $\begin{array}{c}\text { PA } \\
(\mathrm{deg})\end{array}$ & $\begin{array}{c}\text { Speed } \\
\left(\mathrm{km} \mathrm{s}^{-1}\right)\end{array}$ & $\begin{array}{l}\text { Height } \\
\left(\mathrm{R}_{\odot}\right)\end{array}$ & Type & $\begin{array}{l}\text { Time } \\
(\mathrm{UT})\end{array}$ & $\begin{array}{c}\text { PA } \\
(\mathrm{deg})\end{array}$ & $\begin{array}{l}\text { Width } \\
\text { (deg) }\end{array}$ & $\begin{array}{c}\text { Speed } \\
\left(\mathrm{km} \mathrm{s}^{-1}\right)\end{array}$ & Core \\
\hline 047 & 1998 Nov 3 & $04: 26$ & 124 & 65.4 & 1.24 & $\mathrm{R}$ & $05: 18$ & 122 & 16 & 214 & $\mathrm{~N}$ \\
\hline 048 & 1998 Dec 2 & $05: 46$ & 228 & 23.1 & 1.28 & $\mathrm{R}$ & $06: 30$ & 215 & 6 & 655 & $\mathrm{~N}$ \\
\hline 049 & 1998 Dec 16 & $00: 21$ & 222 & 11.5 & 1.15 & $\mathrm{~T}$ & $\mathrm{~N}$ & $\ldots$ & $\ldots$ & $\ldots$ & $\ldots$ \\
\hline 050 & 1999 Feb 8 & $04: 41$ & 52 & 33.1 & 1.38 & $\mathrm{R}$ & $05: 57$ & 92 & 50 & 379 & $\mathrm{~N}$ \\
\hline 051 & 1999 Feb 9 & $00: 41$ & 34 & 110.4 & 1.80 & $\mathrm{R}$ & $01: 30$ & 47 & 60 & 853 & $\mathrm{Y}$ \\
\hline 052 & 1999 Feb 25 & $01: 51$ & 310 & 56.7 & 2.23 & $\mathrm{R}$ & $03: 26$ & 303 & 60 & 766 & $\mathrm{Y}$ \\
\hline 053 & 1999 Feb 27 & $23: 01$ & 304 & 110.6 & 1.63 & $\mathrm{R}$ & $23: 26$ & 302 & 23 & 662 & $\mathrm{Y}$ \\
\hline 054 & 1999 Mar 7 & $23: 31$ & 252 & 73.3 & 1.23 & $\mathrm{R}$ & $23: 54$ & 238 & 14 & 586 & $\mathrm{~N}$ \\
\hline 055 & 1999 Mar 13 & $05: 51$ & 220 & 37.5 & 1.21 & $\mathrm{R}$ & $06: 54$ & 255 & 27 & 580 & $\mathrm{~N}$ \\
\hline 056 & 1999 Mar 17 & $01: 21$ & 315 & 24.6 & 1.36 & $\mathrm{R}$ & $01: 26$ & 314 & 61 & 188 & $\mathrm{Y}$ \\
\hline 057 & 1999 Apr 3 & $00: 41$ & 311 & 15.5 & 1.41 & $\mathrm{R}$ & $\mathrm{N}$ & $\ldots$ & $\cdots$ & $\ldots$ & $\ldots$ \\
\hline 058 & 1999 Apr 5 & 00:41 & 223 & 1.8 & 1.21 & $\mathrm{R}$ & $01: 54$ & 258 & 53 & 471 & $\mathrm{~N}$ \\
\hline 059 & 1999 Apr 23 & $22: 46$ & 143 & -3.9 & 1.19 & $\mathrm{~T}$ & $\mathrm{~N}$ & $\ldots$ & $\ldots$ & $\ldots$ & $\ldots$ \\
\hline 060 & 1999 May 8 & $23: 36$ & 69 & 97.4 & 1.25 & $\mathrm{R}$ & $00: 26^{\mathrm{a}}$ & 64 & 25 & 427 & $\mathrm{~N}$ \\
\hline 061 & 1999 May 12 & $05: 56$ & 154 & -20.4 & 1.11 & $\mathrm{~T}$ & $\mathrm{~N}$ & $\ldots$ & $\ldots$ & $\ldots$ & $\ldots$ \\
\hline 062 & 1999 May 14 & $05: 36$ & 238 & 84.2 & 1.51 & $\mathrm{R}$ & $06: 50$ & 234 & 46 & 592 & $\mathrm{Y}$ \\
\hline 063 & 1999 May 17 & $00: 56$ & 320 & 47.2 & 1.58 & $\mathrm{R}$ & $00: 50$ & 293 & 113 & 503 & $\mathrm{Y}$ \\
\hline 064 & 1999 Jun 11 & $01: 11$ & 36 & 7.8 & 1.17 & $\mathrm{R}$ & $00: 50$ & 55 & 22 & 193 & $\mathrm{~N}$ \\
\hline 065 & 1999 Jun 15 & $01: 21$ & 244 & 2.5 & 1.14 & $\mathrm{~T}$ & $\mathrm{~S}$ & $\ldots$ & $\ldots$ & $\ldots$ & $\ldots$ \\
\hline 066 & 1999 Jun 16 & 04:01 & 59 & 114.6 & 1.45 & $\mathrm{R}$ & $04: 54$ & 63 & 107 & 979 & $\mathrm{Y}$ \\
\hline 067 & 1999 Jun 30 & $05: 31$ & 323 & 25.5 & 1.25 & $\mathrm{R}$ & $\mathrm{N}$ & $\ldots$ & $\ldots$ & $\ldots$ & $\ldots$ \\
\hline 068 & 1999 Jul 9 & 03:41 & 296 & 22.5 & 1.38 & $\mathrm{R}$ & $05: 54$ & 309 & 66 & 533 & $\mathrm{Y}$ \\
\hline 069 & 1999 Jul 10 & $02: 11$ & 122 & 74.5 & 1.36 & $\mathrm{R}$ & $04: 31$ & 98 & 66 & 476 & $\mathrm{Y}$ \\
\hline 070 & 1999 Jul 15 & 01:01 & 178 & 5.1 & 1.22 & $\mathrm{R}$ & $\mathrm{N}$ & $\ldots$ & $\ldots$ & $\ldots$ & $\ldots$ \\
\hline 071 & 1999 Jul 16 & 00:49 & 49 & 18.8 & 1.22 & $\mathrm{R}$ & $01: 31$ & 35 & 17 & 300 & $\mathrm{~N}$ \\
\hline 072 & 1999 Jul 22 & $23: 50$ & 105 & 81.2 & 1.31 & $\mathrm{R}$ & $00: 06^{\mathrm{a}}$ & 75 & 134 & 207 & $\mathrm{Y}$ \\
\hline 073 & 1999 Jul 25 & 02:01 & 299 & 12.3 & 1.14 & $\mathrm{R}$ & $\mathrm{N}$ & $\cdots$ & $\ldots$ & $\cdots$ & $\cdots$ \\
\hline 074 & 1999 Jul 27 & $00: 22$ & 51 & 153.1 & 2.19 & $\mathrm{R}$ & 01:31 & 50 & 193 & 768 & $\mathrm{Y}$ \\
\hline 075 & 1999 Aug 11 & 05:01 & 83 & 7.3 & 1.11 & $\mathrm{~T}$ & $08: 30$ & 53 & 24 & 536 & $\mathrm{~N}$ \\
\hline 076 & 1999 Aug 11 & $22: 31$ & 303 & -123.8 & 2.15 & $\mathrm{R}$ & $22: 30$ & 296 & 129 & 466 & $\mathrm{Y}$ \\
\hline 077 & 1999 Aug 11 & $23: 49$ & 308 & 150.1 & 1.93 & $\mathrm{R}$ & $00: 30^{\mathrm{a}}$ & 284 & 106 & 521 & $\mathrm{Y}$ \\
\hline 078 & 1999 Aug 14 & $02: 41$ & 48 & -1.3 & 1.17 & $\mathrm{~T}$ & $\mathrm{~S}$ & $\ldots$ & $\ldots$ & $\ldots$ & $\ldots$ \\
\hline 079 & 1999 Aug 17 & $04: 55$ & 146 & 251.9 & 1.56 & $\mathrm{R}$ & 05:09 & 162 & 265 & 736 & $\mathrm{Y}$ \\
\hline 080 & 1999 Sep 2 & $23: 36$ & 186 & 88.1 & 1.14 & $\mathrm{R}$ & $00: 06^{\mathrm{a}}$ & 184 & 175 & 512 & $\mathrm{Y}$ \\
\hline 081 & 1999 Sep 14 & $05: 36$ & 309 & 34.2 & 1.36 & $\mathrm{R}$ & $06: 30$ & 301 & 122 & 761 & $\mathrm{Y}$ \\
\hline 082 & 1999 Sep 20 & $23: 36$ & 81 & 95.1 & 1.38 & $\mathrm{R}$ & $23: 30$ & 66 & 57 & 547 & $\mathrm{~N}$ \\
\hline 083 & 1999 Sep 21 & $03: 16$ & 295 & 139.6 & 1.58 & $\mathrm{R}$ & 03:30 & 298 & 125 & 1402 & $\mathrm{Y}$ \\
\hline 084 & 1999 Oct 22 & $23: 46$ & 202 & 3.4 & 1.20 & $\mathrm{~T}$ & $01: 26^{\mathrm{a}}$ & 212 & 34 & 405 & $\mathrm{~N}$ \\
\hline 085 & 1999 Oct 23 & 02:06 & 321 & 32.6 & 1.27 & $\mathrm{R}$ & $01: 26$ & 305 & 143 & 1012 & $\mathrm{Y}$ \\
\hline 086 & 1999 Nov 24 & $05: 21$ & 147 & 1.4 & 1.22 & $\mathrm{~T}$ & $\mathrm{~N}$ & $\ldots$ & $\ldots$ & $\ldots$ & $\ldots$ \\
\hline 087 & 1999 Nov 28 & 02:01 & 209 & 117.9 & 1.67 & $\mathrm{R}$ & $02: 30$ & 202 & 19 & 838 & $\mathrm{Y}$ \\
\hline 088 & 1999 Dec 13 & 05:01 & 129 & 67.9 & 1.20 & $\mathrm{R}$ & $\mathrm{N}$ & $\ldots$ & $\ldots$ & $\ldots$ & $\ldots$ \\
\hline 089 & 1999 Dec 16 & 05:01 & 56 & 75.9 & 1.56 & $\mathrm{R}$ & $05: 30$ & 72 & 70 & 204 & $\mathrm{~N}$ \\
\hline 090 & 2000 Jan 4 & $03: 21$ & 294 & 147.9 & 1.40 & $\mathrm{R}$ & $03: 30$ & 309 & 40 & 1227 & $\mathrm{Y}$ \\
\hline 091 & 2000 Jan 18 & 01:41 & 146 & 5.2 & 1.25 & $\mathrm{~T}$ & $\mathrm{~S}$ & $\ldots$ & $\ldots$ & $\ldots$ & $\ldots$ \\
\hline 092 & 2000 Jan 31 & $00: 51$ & 224 & 55.3 & 1.60 & $\mathrm{R}$ & 01:31 & 226 & 92 & 366 & $\mathrm{Y}$ \\
\hline
\end{tabular}


This is an unedited preprint of an article accepted for publication in Astrophysical Journal. The final published article may differ from this preprint.

Copyright 2002 by The American Astronomical Society. Please cite as 'ApJ preprint doi:10.1086/367614'.

Table 1-Continued

\begin{tabular}{|c|c|c|c|c|c|c|c|c|c|c|c|}
\hline & \multicolumn{6}{|c|}{$\mathrm{PE}$} & \multicolumn{5}{|c|}{$\mathrm{CME}$} \\
\hline & Date & $\begin{array}{l}\text { Time } \\
(\mathrm{UT})\end{array}$ & $\begin{array}{c}\text { PA } \\
(\operatorname{deg})\end{array}$ & $\begin{array}{c}\text { Speed } \\
\left(\mathrm{km} \mathrm{s}^{-1}\right)\end{array}$ & $\begin{array}{c}\text { Height } \\
\left(\mathrm{R}_{\odot}\right)\end{array}$ & Type & $\begin{array}{l}\text { Time } \\
(\mathrm{UT})\end{array}$ & $\begin{array}{c}\text { PA } \\
(\text { deg })\end{array}$ & $\begin{array}{c}\text { Width } \\
\text { (deg) }\end{array}$ & $\begin{array}{c}\text { Speed } \\
\left(\mathrm{km} \mathrm{s}^{-1}\right)\end{array}$ & Core \\
\hline 093 & 2000 Feb 10 & 00:31 & 319 & 77.5 & 1.35 & $\mathrm{R}$ & $\mathrm{N}$ & $\ldots$ & $\ldots$ & $\ldots$ & $\ldots$ \\
\hline 094 & 2000 Feb 12 & $03: 21$ & 25 & 22.3 & 1.22 & $\mathrm{R}$ & $\mathrm{N}$ & $\ldots$ & $\ldots$ & $\ldots$ & $\ldots$ \\
\hline 095 & 2000 Feb 22 & $03: 21$ & 289 & 44.3 & 1.23 & $\mathrm{R}$ & $03: 54$ & 273 & 19 & 667 & $\mathrm{~N}$ \\
\hline 096 & 2000 Feb 25 & 04:41 & 348 & 24.4 & 1.37 & $\mathrm{R}$ & $05: 30$ & 317 & 61 & 307 & $\mathrm{Y}$ \\
\hline 097 & 2000 Feb 27 & 00:01 & 27 & 379.5 & 2.55 & $\mathrm{R}$ & $23: 54^{\mathrm{b}}$ & 357 & 104 & 668 & $\mathrm{Y}$ \\
\hline 098 & 2000 Mar 8 & 00:31 & 160 & 2.7 & 1.18 & $\mathrm{~T}$ & $\mathrm{~N}$ & $\ldots$ & $\ldots$ & $\ldots$ & $\ldots$ \\
\hline 099 & 2000 Mar 9 & $01: 21$ & 162 & 7.4 & 1.11 & $\mathrm{R}$ & $01: 31$ & 172 & 51 & 318 & $\mathrm{~N}$ \\
\hline 100 & 2000 Mar 13 & $23: 41$ & 140 & 87.8 & 1.43 & $\mathrm{R}$ & $\mathrm{N}$ & $\ldots$ & $\ldots$ & $\ldots$ & $\ldots$ \\
\hline 101 & 2000 Mar 14 & $02: 51$ & 234 & 83.7 & 1.33 & $\mathrm{R}$ & $03: 26$ & 228 & 67 & 220 & $\mathrm{Y}$ \\
\hline 102 & 2000 Mar 17 & 01:01 & 96 & 141.8 & 1.42 & $\mathrm{R}$ & $01: 28$ & 130 & 46 & 323 & $\mathrm{Y}$ \\
\hline 103 & 2000 Mar 18 & $01: 51$ & 46 & 127.1 & 1.39 & $\mathrm{R}$ & $02: 30$ & 52 & 7 & 492 & $\mathrm{~N}$ \\
\hline 104 & 2000 Mar 19 & $05: 11$ & 343 & 57.5 & 1.30 & $\mathrm{R}$ & 06:06 & 344 & 63 & 194 & $\mathrm{Y}$ \\
\hline 105 & 2000 Mar 28 & 23:01 & 327 & 35.7 & 1.49 & $\mathrm{R}$ & $00: 14^{\mathrm{a}}$ & 346 & 52 & $\ldots$ & $\mathrm{Y}$ \\
\hline 106 & 2000 Apr 20 & 00:06 & 236 & 5.5 & 1.17 & $\mathrm{~T}$ & $00: 30$ & 220 & 141 & 737 & $\mathrm{Y}$ \\
\hline 107 & 2000 Apr 23 & $23: 02$ & 342 & 86.8 & 1.29 & $\mathrm{R}$ & $23: 30$ & 321 & 48 & 232 & $\mathrm{~N}$ \\
\hline 108 & 2000 May 4 & $04: 46$ & 262 & 37.0 & 1.31 & $\mathrm{R}$ & $04: 50$ & 239 & 62 & 1064 & $\mathrm{Y}$ \\
\hline 109 & 2000 May 11 & $23: 06$ & 165 & 94.3 & 1.96 & $\mathrm{R}$ & $23: 26$ & 186 & 141 & 716 & $\mathrm{Y}$ \\
\hline 110 & 2000 May 11 & $23: 06$ & 184 & 157.5 & 1.61 & $\mathrm{R}$ & $23: 50$ & 187 & 130 & 674 & $\mathrm{Y}$ \\
\hline 111 & 2000 May 20 & 06:06 & 210 & 15.1 & 1.27 & $\mathrm{~T}$ & $06: 26$ & 187 & 75 & 557 & $\mathrm{Y}$ \\
\hline 112 & 2000 Jun 2 & $04: 26$ & 39 & 44.7 & 1.20 & $\mathrm{R}$ & $04: 30$ & 89 & 90 & 526 & $\mathrm{Y}$ \\
\hline 113 & 2000 Jun 15 & $01: 26$ & 309 & 127.8 & 1.36 & $\mathrm{R}$ & $01: 50$ & 335 & 39 & 758 & $\mathrm{Y}$ \\
\hline 114 & 2000 Jun 16 & $22: 46$ & 236 & 35.7 & 1.41 & $\mathrm{R}$ & $23: 30$ & 256 & 46 & 597 & $\mathrm{Y}$ \\
\hline 115 & 2000 Jun 23 & $00: 26$ & 296 & 71.8 & 1.34 & $\mathrm{R}$ & $00: 54$ & 301 & 37 & 607 & $\mathrm{Y}$ \\
\hline 116 & 2000 Jun 23 & $05: 46$ & 190 & 5.3 & 1.28 & $\mathrm{R}$ & 08:06 & 189 & 16 & 317 & $\mathrm{~N}$ \\
\hline 117 & 2000 Jun 26 & $00: 56$ & 304 & 189.7 & 1.21 & $\mathrm{R}$ & $01: 31$ & 310 & 55 & 654 & $\mathrm{Y}$ \\
\hline 118 & 2000 Jun 27 & 00:06 & 323 & 7.6 & 1.16 & $\mathrm{R}$ & $23: 54^{\mathrm{b}}$ & 321 & 61 & 204 & $\mathrm{~N}$ \\
\hline 119 & 2000 Jul 6 & $00: 16$ & 330 & 44.9 & 1.28 & $\mathrm{R}$ & $00: 50$ & 352 & 41 & 888 & $\mathrm{Y}$ \\
\hline 120 & 2000 Jul 9 & $03: 36$ & 255 & 4.9 & 1.14 & $\mathrm{~T}$ & $\mathrm{~N}$ & $\ldots$ & $\ldots$ & $\ldots$ & $\ldots$ \\
\hline 121 & $2000 \mathrm{Jul} 13$ & $00: 26$ & 261 & 63.5 & 1.31 & $\mathrm{R}$ & $\mathrm{N}$ & $\ldots$ & $\ldots$ & $\ldots$ & $\ldots$ \\
\hline 122 & $2000 \mathrm{Jul} 15$ & $23: 16$ & 105 & 130.1 & 1.33 & $\mathrm{R}$ & $01: 55^{\mathrm{a}}$ & 79 & 25 & 389 & $\mathrm{Y}$ \\
\hline 123 & $2000 \mathrm{Jul} 27$ & 04:06 & 120 & 38.4 & 1.18 & $\mathrm{R}$ & $\mathrm{N}$ & $\ldots$ & $\ldots$ & $\ldots$ & $\ldots$ \\
\hline 124 & 2000 Aug 12 & $04: 26$ & 266 & 0.3 & 1.24 & $\mathrm{~T}$ & $\mathrm{~N}$ & $\ldots$ & $\ldots$ & $\ldots$ & $\ldots$ \\
\hline 125 & 2000 Aug 12 & $22: 56$ & 79 & 37.8 & 1.44 & $\mathrm{R}$ & $23: 54$ & 63 & 46 & 676 & $\mathrm{~N}$ \\
\hline 126 & 2000 Aug 15 & $22: 46$ & 345 & 1.6 & 1.31 & $\mathrm{R}$ & $\mathrm{N}$ & $\ldots$ & $\ldots$ & $\ldots$ & $\ldots$ \\
\hline 127 & 2000 Aug 20 & $04: 36$ & 241 & 82.8 & 1.37 & $\mathrm{R}$ & $05: 30$ & 220 & 95 & 549 & $\mathrm{Y}$ \\
\hline 128 & 2000 Aug 24 & $22: 46$ & 102 & 7.0 & 1.33 & $\mathrm{R}$ & $\mathrm{N}$ & $\ldots$ & $\ldots$ & $\cdots$ & $\ldots$ \\
\hline 129 & 2000 Aug 28 & $00: 16$ & 63 & 79.8 & 1.57 & $\mathrm{R}$ & $00: 54$ & 67 & 133 & 542 & $\mathrm{Y}$ \\
\hline 130 & 2000 Aug 31 & $06: 16$ & 106 & 63.9 & 1.37 & $\mathrm{R}$ & $06: 54$ & 102 & 78 & 462 & $\mathrm{Y}$ \\
\hline 131 & 2000 Sep 9 & $22: 46$ & 312 & 12.9 & 1.15 & $\mathrm{~T}$ & $\mathrm{~S}$ & $\ldots$ & $\ldots$ & $\ldots$ & $\ldots$ \\
\hline 132 & 2000 Sep 12 & $23: 06$ & 102 & 28.0 & 1.24 & $\mathrm{R}$ & $23: 54$ & 109 & 34 & 159 & $\mathrm{~N}$ \\
\hline 133 & 2000 Oct 6 & $01: 26$ & 309 & 37.3 & 1.48 & $\mathrm{R}$ & $01: 50$ & 327 & 41 & 382 & $\mathrm{~N}$ \\
\hline 134 & 2000 Oct 15 & $02: 06$ & 213 & 36.5 & 1.33 & $\mathrm{R}$ & $02: 50$ & 200 & 63 & 594 & $\mathrm{Y}$ \\
\hline 135 & 2000 Oct 22 & $00: 06$ & 123 & 130.1 & 2.35 & $\mathrm{R}$ & $00: 50$ & 103 & 236 & 1024 & $\mathrm{Y}$ \\
\hline 136 & 2000 Nov 4 & $01: 10$ & 237 & 63.6 & 1.43 & $\mathrm{R}$ & $01: 50$ & 213 & 100 & 763 & $\mathrm{Y}$ \\
\hline 137 & 2000 Nov 20 & $00: 50$ & 13 & 8.5 & 1.16 & $\mathrm{~T}$ & 02:06 & 14 & 48 & 556 & $\mathrm{~N}$ \\
\hline 138 & 2000 Nov 24 & $00: 40$ & 241 & 172.2 & 1.73 & $\mathrm{R}$ & $00: 54$ & 236 & 93 & 668 & $\mathrm{Y}$ \\
\hline
\end{tabular}


This is an unedited preprint of an article accepted for publication in Astrophysical Journal. The final published article may differ from this preprint.

Copyright 2002 by The American Astronomical Society. Please cite as 'ApJ preprint doi:10.1086/367614'.

Table 1 -Continued

\begin{tabular}{|c|c|c|c|c|c|c|c|c|c|c|c|}
\hline & \multicolumn{6}{|c|}{$\mathrm{PE}$} & \multicolumn{5}{|c|}{$\mathrm{CME}$} \\
\hline & Date & $\begin{array}{l}\text { Time } \\
\text { (UT) }\end{array}$ & $\begin{array}{c}\text { PA } \\
(\operatorname{deg})\end{array}$ & $\begin{array}{c}\text { Speed } \\
\left(\mathrm{km} \mathrm{s}^{-1}\right)\end{array}$ & $\begin{array}{c}\text { Height } \\
\left(\mathrm{R}_{\odot}\right)\end{array}$ & Type & $\begin{array}{l}\text { Time } \\
(\mathrm{UT})\end{array}$ & $\begin{array}{c}\text { PA } \\
(\text { deg })\end{array}$ & $\begin{array}{c}\text { Width } \\
\text { (deg) }\end{array}$ & $\begin{array}{c}\text { Speed } \\
\left(\mathrm{km} \mathrm{s}^{-1}\right)\end{array}$ & Core \\
\hline 139 & 2000 Nov 27 & $22: 50$ & 130 & -299.9 & 1.45 & $\mathrm{R}$ & $23: 54$ & 123 & 57 & 474 & $\mathrm{Y}$ \\
\hline 140 & 2000 Dec 3 & $05: 40$ & 302 & 39.0 & 1.39 & $\mathrm{R}$ & $05: 50$ & 301 & 147 & 751 & $\mathrm{Y}$ \\
\hline 141 & 2000 Dec 27 & 04:00 & 244 & 39.6 & 1.33 & $\mathrm{R}$ & 04:06 & 249 & 134 & 472 & $\mathrm{Y}$ \\
\hline 142 & 2001 Jan 7 & $03: 30$ & 302 & 129.1 & 2.02 & $\mathrm{R}$ & 04:06 & 298 & 76 & 633 & $\mathrm{Y}$ \\
\hline 143 & 2001 Jan 14 & $05: 35$ & 320 & 48.9 & 1.34 & $\mathrm{R}$ & $06: 30$ & 327 & 134 & 945 & $\mathrm{Y}$ \\
\hline 144 & 2001 Jan 25 & $23: 05$ & 192 & 16.3 & 1.26 & $\mathrm{R}$ & $00: 54^{\mathrm{a}}$ & 211 & 23 & 267 & $\mathrm{~N}$ \\
\hline 145 & 2001 Feb 2 & $23: 55$ & 71 & 235.7 & 1.58 & $\mathrm{R}$ & $00: 30^{\mathrm{a}}$ & 86 & 203 & 639 & $\mathrm{Y}$ \\
\hline 146 & 2001 Feb 9 & $23: 05$ & 217 & 145.5 & 2.59 & $\mathrm{R}$ & $23: 06$ & 229 & 199 & 651 & $\mathrm{Y}$ \\
\hline 147 & 2001 Feb 10 & $05: 45$ & 326 & 67.4 & 1.31 & $\mathrm{R}$ & $06: 30$ & 306 & 41 & 462 & $\mathrm{Y}$ \\
\hline 148 & 2001 Mar 1 & 04:05 & 286 & 38.2 & 1.19 & $\mathrm{R}$ & 04:06 & 292 & 91 & 379 & $\mathrm{Y}$ \\
\hline 149 & 2001 Mar 11 & $04: 45$ & 211 & 77.1 & 1.62 & $\mathrm{R}$ & $05: 50$ & 230 & 165 & 404 & $\mathrm{Y}$ \\
\hline 150 & 2001 Mar 18 & $00: 15$ & 303 & 18.2 & 1.25 & $\mathrm{R}$ & $05: 26$ & 291 & 58 & 436 & $\mathrm{Y}$ \\
\hline 151 & 2001 Mar 19 & $00: 45$ & 313 & 19.7 & 1.21 & $\mathrm{R}$ & $04: 50$ & 308 & 19 & 298 & $\mathrm{~N}$ \\
\hline 152 & 2001 Mar 23 & 01:05 & 220 & 24.5 & 1.18 & $\mathrm{R}$ & $\mathrm{N}$ & $\ldots$ & $\ldots$ & $\ldots$ & $\ldots$ \\
\hline 153 & 2001 Apr 3 & $05: 45$ & 254 & 240.4 & 1.86 & $\mathrm{R}$ & $06: 06$ & 250 & 35 & 596 & $\mathrm{Y}$ \\
\hline 154 & 2001 Apr 20 & $03: 15$ & 92 & 8.8 & 1.16 & $\mathrm{R}$ & $04: 30$ & 122 & 81 & 381 & $\mathrm{Y}$ \\
\hline 155 & 2001 Apr 21 & $05: 25$ & 310 & 115.7 & 1.68 & $\mathrm{R}$ & $05: 49$ & 293 & 50 & 360 & $\mathrm{Y}$ \\
\hline 156 & 2001 Apr 22 & $04: 45$ & 142 & 179.7 & 1.47 & $\mathrm{R}$ & $05: 26$ & 166 & 150 & 502 & $\mathrm{Y}$ \\
\hline 157 & 2001 May 6 & $00: 50$ & 67 & 11.2 & 1.21 & $\mathrm{R}$ & $00: 54$ & 96 & 31 & 351 & $\mathrm{~N}$ \\
\hline 158 & 2001 May 6 & $03: 50$ & 56 & 16.0 & 1.24 & $\mathrm{R}$ & $05: 30$ & 92 & 49 & 611 & $\mathrm{Y}$ \\
\hline 159 & 2001 May 12 & 05:00 & 56 & 22.1 & 1.17 & $\mathrm{R}$ & $\mathrm{N}$ & $\ldots$ & $\ldots$ & $\ldots$ & $\ldots$ \\
\hline 160 & 2001 May 14 & $03: 40$ & 59 & 74.0 & 1.39 & $\mathrm{R}$ & 04:00 & 67 & 67 & 892 & $\mathrm{Y}$ \\
\hline 161 & 2001 May 21 & $00: 40$ & 47 & 29.7 & 1.28 & $\mathrm{R}$ & $01: 50$ & 32 & 55 & 736 & $\mathrm{Y}$ \\
\hline 162 & 2001 May 28 & $22: 50$ & 175 & -12.8 & 1.21 & $\mathrm{R}$ & $\mathrm{S}$ & $\ldots$ & $\ldots$ & $\ldots$ & $\ldots$ \\
\hline 163 & 2001 May 30 & $22: 50$ & 245 & 0.7 & 1.18 & $\mathrm{~T}$ & $21: 54$ & 223 & 59 & 169 & $\mathrm{~N}$ \\
\hline 164 & 2001 Jun 4 & $03: 50$ & 322 & 18.2 & 1.18 & $\mathrm{R}$ & 04:06 & 323 & 61 & 664 & $\mathrm{~N}$ \\
\hline 165 & 2001 Jun 18 & $02: 30$ & 55 & 16.1 & 1.18 & $\mathrm{R}$ & $03: 30$ & 48 & 22 & 177 & $\mathrm{~N}$ \\
\hline 166 & 2001 Jul 6 & $22: 50$ & 172 & 11.9 & 1.32 & $\mathrm{R}$ & $\mathrm{N}$ & $\ldots$ & $\ldots$ & $\ldots$ & $\ldots$ \\
\hline 167 & $2001 \mathrm{Jul} 10$ & $22: 50$ & 45 & 5.0 & 1.12 & $\mathrm{~T}$ & $\mathrm{~N}$ & $\ldots$ & $\ldots$ & $\ldots$ & $\ldots$ \\
\hline 168 & $2001 \mathrm{Jul} 12$ & 00:00 & 214 & 24.0 & 1.35 & $\mathrm{R}$ & 00:06 & 240 & 148 & 736 & $\mathrm{Y}$ \\
\hline 169 & $2001 \mathrm{Jul} 18$ & $04: 40$ & 182 & 17.0 & 1.31 & $\mathrm{R}$ & $06: 30$ & 187 & 19 & 529 & $\mathrm{~N}$ \\
\hline 170 & 2001 Jul 20 & $23: 50$ & 215 & -6.3 & 1.16 & $\mathrm{R}$ & $23: 30$ & 204 & 36 & 301 & $\mathrm{Y}$ \\
\hline 171 & 2001 Aug 11 & $01: 20$ & 286 & 106.6 & 1.22 & $\mathrm{R}$ & $01: 54$ & 272 & 83 & 357 & $\mathrm{Y}$ \\
\hline 172 & 2001 Aug 19 & $05: 30$ & 299 & 87.7 & 1.40 & $\mathrm{R}$ & $06: 06$ & 292 & 360 & 556 & $\mathrm{Y}$ \\
\hline 173 & 2001 Aug 29 & 02:00 & 132 & 16.5 & 1.25 & $\mathrm{R}$ & $\mathrm{N}$ & $\ldots$ & $\ldots$ & $\ldots$ & $\ldots$ \\
\hline 174 & 2001 Sep 7 & $01: 40$ & 104 & 14.5 & 1.21 & $\mathrm{R}$ & 02:06 & 99 & 52 & 179 & $\mathrm{Y}$ \\
\hline 175 & 2001 Sep 10 & $02: 40$ & 135 & 73.7 & 1.30 & $\mathrm{R}$ & 03:30 & 127 & 25 & 800 & $\mathrm{Y}$ \\
\hline 176 & 2001 Sep 21 & 02:00 & 151 & 57.5 & 1.28 & $\mathrm{R}$ & $03: 30$ & 177 & 210 & 371 & $\mathrm{Y}$ \\
\hline 177 & 2001 Sep 26 & $01: 50$ & 314 & 21.8 & 1.35 & $\mathrm{R}$ & $03: 52$ & 293 & 97 & 644 & $\mathrm{Y}$ \\
\hline 178 & 2001 Oct 1 & 02:00 & 226 & 117.2 & 1.40 & $\mathrm{R}$ & $01: 54$ & 226 & 68 & 478 & $\mathrm{Y}$ \\
\hline 179 & 2001 Oct 19 & $23: 05$ & 312 & 34.2 & 1.66 & $\mathrm{R}$ & $00: 06^{\mathrm{a}}$ & 272 & 97 & 514 & $\mathrm{Y}$ \\
\hline 180 & 2001 Oct 20 & $03: 23$ & 310 & 21.9 & 1.22 & $\mathrm{R}$ & $05: 26$ & 306 & 54 & 203 & $\mathrm{Y}$ \\
\hline 181 & 2001 Oct 27 & $23: 35$ & 52 & 56.0 & 1.36 & $\mathrm{R}$ & $00: 26^{\mathrm{a}}$ & 85 & 200 & 592 & $\mathrm{Y}$ \\
\hline 182 & 2001 Nov 30 & $00: 25$ & 137 & -10.8 & 1.16 & $\mathrm{~T}$ & $\mathrm{~N}$ & $\ldots$ & $\ldots$ & $\ldots$ & $\ldots$ \\
\hline 183 & 2001 Dec 7 & $01: 15$ & 221 & 54.0 & 1.78 & $\mathrm{R}$ & $02: 30$ & 222 & 76 & 393 & $\mathrm{Y}$ \\
\hline 184 & 2001 Dec 11 & $00: 55$ & 130 & -8.0 & 1.09 & $\mathrm{~T}$ & $\mathrm{~S}$ & $\ldots$ & $\ldots$ & $\ldots$ & $\ldots$ \\
\hline
\end{tabular}


This is an unedited preprint of an article accepted for publication in Astrophysical Journal. The final published article may differ from this preprint.

Copyright 2002 by The American Astronomical Society. Please cite as 'ApJ preprint doi:10.1086/367614'.

Table 1 - Continued

\begin{tabular}{|c|c|c|c|c|c|c|c|c|c|c|c|}
\hline & \multicolumn{6}{|c|}{$\mathrm{PE}$} & \multicolumn{5}{|c|}{$\mathrm{CME}$} \\
\hline & Date & $\begin{array}{l}\text { Time } \\
(\mathrm{UT})\end{array}$ & $\begin{array}{c}\text { PA } \\
(\mathrm{deg})\end{array}$ & $\begin{array}{c}\text { Speed } \\
\left(\mathrm{km} \mathrm{s}^{-1}\right)\end{array}$ & $\begin{array}{c}\text { Height } \\
\left(\mathrm{R}_{\odot}\right)\end{array}$ & Type & $\begin{array}{l}\text { Time } \\
(\mathrm{UT})\end{array}$ & $\begin{array}{c}\text { PA } \\
(\text { deg })\end{array}$ & $\begin{array}{c}\text { Width } \\
\text { (deg) }\end{array}$ & $\begin{array}{c}\text { Speed } \\
\left(\mathrm{km} \mathrm{s}^{-1}\right)\end{array}$ & Core \\
\hline 185 & 2001 Dec 19 & $23: 45$ & 136 & 97.0 & 1.75 & $\mathrm{R}$ & $00: 30^{\mathrm{a}}$ & 113 & 108 & 769 & $\mathrm{Y}$ \\
\hline 186 & 2001 Dec 28 & $23: 05$ & 116 & 2.3 & 1.26 & $\mathrm{R}$ & $\mathrm{N}$ & $\ldots$ & $\ldots$ & $\ldots$ & $\ldots$ \\
\hline
\end{tabular}

${ }^{a}$ Next day

${ }^{\mathrm{b}}$ Previous Day 
This is an unedited preprint of an article accepted for publication in Astrophysical Journal. The final published article may differ from this preprint.

Copyright 2002 by The American Astronomical Society. Please cite as 'ApJ preprint doi:10.1086/367614'.

Table 2. Summary of statistical properties of the prominence events

\begin{tabular}{llll}
\hline \hline & Transverse & Radial & ALL \\
\hline Total \# & 34 & 152 & 186 \\
Average Maximum height $\left(\mathrm{R}_{\odot}\right)$ & 1.16 & 1.40 & 1.36 \\
Average Speed $\left(\mathrm{km} \mathrm{s}^{-1}\right)$ & 9.5 & 64.5 & 56.3 \\
\# with CMEs & $8(4 \%)$ & $126(68 \%)$ & $134(72 \%)$ \\
\# without CMEs & $26(14 \%)$ & $26(14 \%)$ & $52(28 \%)$ \\
$\quad$ \# with CME Core & $3(2 \%)$ & $95(71 \%)$ & $98(73 \%)$ \\
$\quad$ \# without CME Core & $5(4 \%)$ & $31(23 \%)$ & $36(27 \%)$ \\
\hline
\end{tabular}

